\title{
Price dynamics and collusion under short-run price commitments
}

Citation for published version (APA):

Leufkens, K., \& Peeters, R. J. A. P. (2008). Price dynamics and collusion under short-run price commitments. METEOR, Maastricht University School of Business and Economics. METEOR Research Memorandum No. 052 https://doi.org/10.26481/umamet.2008052

Document status and date:

Published: 01/01/2008

DOI:

10.26481/umamet.2008052

Document Version:

Publisher's PDF, also known as Version of record

\section{Please check the document version of this publication:}

- A submitted manuscript is the version of the article upon submission and before peer-review. There can be important differences between the submitted version and the official published version of record.

People interested in the research are advised to contact the author for the final version of the publication, or visit the DOI to the publisher's website.

- The final author version and the galley proof are versions of the publication after peer review.

- The final published version features the final layout of the paper including the volume, issue and page numbers.

Link to publication

\footnotetext{
General rights rights.

- You may freely distribute the URL identifying the publication in the public portal. please follow below link for the End User Agreement:

www.umlib.nl/taverne-license

Take down policy

If you believe that this document breaches copyright please contact us at:

repository@maastrichtuniversity.nl

providing details and we will investigate your claim.
}

Copyright and moral rights for the publications made accessible in the public portal are retained by the authors and/or other copyright owners and it is a condition of accessing publications that users recognise and abide by the legal requirements associated with these

- Users may download and print one copy of any publication from the public portal for the purpose of private study or research.

- You may not further distribute the material or use it for any profit-making activity or commercial gain

If the publication is distributed under the terms of Article $25 \mathrm{fa}$ of the Dutch Copyright Act, indicated by the "Taverne" license above, 
Kasper Leufkens, Ronald Peeters

Price dynamics and collusion under short-run price commitments

$\mathrm{RM} / 08 / 052$

JEL code: C91, D43

\section{METE@R}

Maastricht research school of Economics of TEchnology and ORganizations

Universiteit Maastricht

Faculty of Economics and Business Administration P.O. Box 616

NL - 6200 MD Maastricht

phone : ++31433883830

fax : ++31433884873 


\title{
Price dynamics and collusion under short-run price commitments*
}

\author{
Kasper Leufkens $^{\dagger} \quad$ Ronald Peeters ${ }^{\ddagger}$
}

December 18, 2008

\begin{abstract}
We consider a dynamic homogenous oligopoly in which firms set prices repeatedly. Theory predicts that short-run price commitments have an increasing impact on profits and may lead to less price stability. The experiments that we conduct provide support for the first effect and against the second effect when a random ending rule is applied. Application of a fixed ending rule seems to reverse these findings, but none of the effects is significant.
\end{abstract}

JEL Classification Codes: C91; D43.

Keywords: Short-run price commitments; Alternating-move games; Collusion; Price Dynamics; Experiment.

\section{Introduction}

Nowadays, Japanese grocery stores use digital displays to post the prices of their products, whereas most European and US grocery stores use printed prices. ${ }^{1}$ The costs of implementing price changes are negligible with these digital price displays, whereas these costs are substantial otherwise. This causes inflexibility towards price alterations in Europe and US, where grocery stores are committed to prices in the short run. The (in)flexibility in adaptation of the strategic variable could influence the competitiveness in a market.

In this paper we investigate, by means of a laboratory experiment, whether short-run price commitments facilitate collusion (higher profits) and less active price dynamics. Thereto, we consider the dynamic homogenous duopoly model of Maskin and Tirole (1988), where shortrun price commitments are implemented by means of an alternating price mechanism; that is: the firms set their prices alternately over an infinite horizon. ${ }^{2}$ Maskin and Tirole (1988)

\footnotetext{
${ }^{*}$ We thank conference participants in Alicante (IMEBE 2008) and Bradley Ruffle for helpful comments and suggestions.

${ }^{\dagger}$ Department of Economics, Maastricht University, P.O. Box 616, 6200 MD Maastricht, The Netherlands.

${ }^{\ddagger}$ Corresponding author. Department of Economics, Maastricht University, P.O. Box 616, 6200 MD Maastricht, The Netherlands. Email: R.Peeters@algec.unimaas.nl.

${ }^{1}$ The use of digital price displays have only recently started in a minor number of European grocery stores.

${ }^{2}$ An alternative approach would be to endogenize the timing of price adaption. However, this is likely to result in a lack of dynamics, as it is found in experiments that many subjects have some sort of preference for delay (Tykocinski and Ruffle, 2003; Fonseca et al., 2006).
} 
show that two stationary subgame-perfect equilibria coexist: a focal price equilibrium and an equilibrium that consists of Edgeworth cycles. Both equilibria render higher profits for the firms than what would be generated without being committed to the chosen prices for two consecutive periods.

Our experiment has two treatment variables that each may take one of two possible values. The first treatment variable is the price setting mechanism: subjects make their decisions either alternately or simultaneously. Here, the treatments with simultaneous moves are used as a benchmark against which the treatments with alternating moves are mirrored in order to assess the impact of the short-run price commitment. The second treatment variable considers the termination rule that either follows a random stopping rule or a fixed ending rule. The random stopping rule mimics an infinite horizon with time discounting. Although several experimental studies find (apart from an end game effect) no behavioral difference between treatments with a long finite horizon and one which approximates an infinite horizon by the device of a stopping probability (Selten and Stoecker, 1986; Engle-Warnick and Slonim, 2004; Normann and Wallace, 2006), Dal Bó (2005) finds higher levels of cooperation for settings in which the infinitely repeated game was mimicked by a stopping probability. In addition, Selten et al. (1997) argue that an infinite horizon cannot credibly be implemented in the lab via a random stopping rule. Therefore, we decided to conduct treatments with a fixed ending rule as well.

We find that short-run price commitments have an increasing impact on firms' profits and lead to more price stability and less price cycles when interaction takes place over an infinite horizon. Apparently, short-run price commitments support firms to coordinate on anticompetitive prices. However, when the era of strategic interaction is finite, short-run price commitments have no significant impact on behavior and performance. Thereby, our results support the hypothesis of Dal Bó (2005) that the credible threat of future retaliation, that is present in the infinite horizon setting, casts "the shadow of the future" that overcomes opportunistic behavior and supports cooperation.

The remaining of the paper is structured as follows. In the next section we present the experimental setting in detail. Moreover, we present the theoretical predictions for the infinite horizon and finite horizon version of the model. Strikingly, the subgame-perfect equilibrium strategies of the finite horizon model with alternating moves converge to non-stationary behavior with a cyclical pricing pattern on the equilibrium path when the horizon lengthens. In Section 3 the experimental design and procedures are clarified. Next, in Section 4, the results are reported. Finally, an extensive discussion of the results and the related literature follows in Section 5.

\section{The setting}

The setting that we consider is precisely the illustrating example of the exogenous-timing duopoly model of Maskin and Tirole (1988). Two firms, $A$ and $B$, compete in a homogenous 
product market with prices being the strategic variable. The prices that the firms can charge are the seven integers between (and including) 0 and 6 . Given the firms' prices at a certain period, $p^{A}$ and $p^{B}$, the market price (for that period) equals $p^{*}=\min \left\{p^{A} ; p^{B}\right\}$. The market demand is given by $D\left(p^{*}\right)=6-p^{*}$. Firms do not incur any costs for production. Consequently, the market profit equals $\Pi\left(p^{*}\right)=p^{*} \cdot D\left(p^{*}\right)$. Table 1 summarizes the possible market prices and the resulting market demand and market profit.

\begin{tabular}{llllllll}
\hline Market price & 0 & 1 & 2 & 3 & 4 & 5 & 6 \\
Market demand & 6 & 5 & 4 & 3 & 2 & 1 & 0 \\
\hline Market profit & 0 & 5 & 8 & 9 & 8 & 5 & 0 \\
\hline
\end{tabular}

Table 1: The output and profit for the seller with the lowest price.

The products are homogeneous and therefore only the firm with the lowest price sells output. This means that if a firm has the unique lowest price, this firm receives the full market profit. In case both firms charge the same price, the market demand and the market profit are split equally among them.

When firms set prices simultaneously in this setting, the equilibrium prediction for a one-shot interaction is that both firms set prices at 0 or both firms set prices at 1 . By a backwards induction argument it follows that in a recurrent interaction over a finite horizon, the subgame-perfect equilibrium prediction is that in each period both firms set equal prices -again, either 0 or $1-$, though possibly coordinating on different prices across periods. In a recurrent interaction over an infinite horizon (with discounted profits), the stationary subgame-perfect equilibrium prediction is that the firms both set either the price constantly at 0 or at 1 . Notice, however, that setting the price at 1 weakly dominates setting the price at 0 .

Next, following Maskin and Tirole (1988), consider this setting when firms interact dynamically in discrete time and can adapt their prices alternately. In the periods in which a firm cannot adapt its price, the price remains equal to the price set in the previous period. Consequently, firms set prices for two periods. This alternating move structure captures the idea of short-run price commitments. In the following subsections we discuss the (stationary) subgame-perfect equilibrium predictions for interactions over an infinite and a finite time horizon separately.

\section{$2.1 \quad$ Infinite horizon}

Suppose that the time horizon is infinite and future profits are discounted by a factor $\delta$. It is assumed that this discount factor is sufficiently close to, but strictly smaller than one. Firms maximize the present value of the infinite stream of profits at any period. Maskin and Tirole (1988) solve this setting for strategies that only depend on the payoff relevant state, which is in this case the price set by the other firm in the previous period. Consequently, strategies are dynamic reaction functions that give a response price for each price set by the other firm. 
There are two stationary subgame-perfect equilibria that coexist: a focal price equilibrium and an equilibrium that consists of Edgeworth cycles. ${ }^{3}$

The details of the focal price equilibrium are illustrated in Figure 1. It shows the symmetric equilibrium strategy (left panel) and the prices set along the equilibrium path (right panel). As soon as one of the two firms sets a price of 3, prices remain there ever after. From any price above 3 , the equilibrium response brings the price immediately down to 3 . From prices below 3, prices are not instantly changed to 3, but do end up there with probability one. Bringing the price up from 1 to 3 is costly and therefore each firm prefers the other firm to do so. The probability $\beta(\delta)$ is determined in such a way that the opponent firm is indifferent between raising and not raising the price. This equilibrium predicts that, probably after a short period, the market price is constantly 3 and the market demand and profit are split equally such that each firm makes a profit of 4.5 in all periods.

\begin{tabular}{ccl}
\hline Price & Response price \\
\hline 6 & 3 \\
5 & 3 & \\
4 & 3 & \\
3 & 3 & \\
2 & 1 & with probability $\beta(\delta)$ \\
1 & 1 & \\
\multicolumn{3}{c}{$\beta$} \\
0 & 3 & with probability $1-\beta(\delta)$ \\
\hline \multicolumn{3}{c}{$\beta(\delta) \equiv(5+\delta) /\left(5 \delta+9 \delta^{2}\right)$} \\
\hline
\end{tabular}

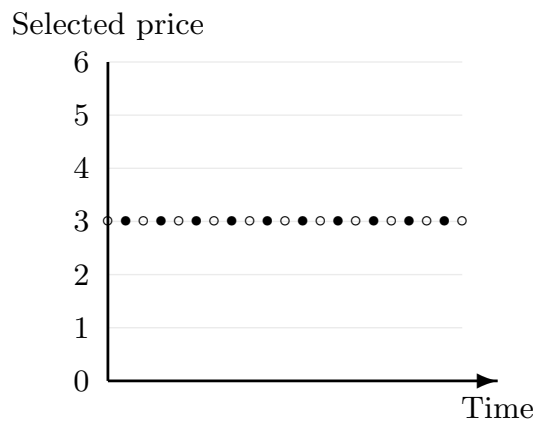

Figure 1: Focal price equilibrium. Left panel: symmetric stationary subgame-perfect equilibrium strategy. Right panel: selected price by the respective firm in the respective period ( $\circ=$ firm $A$; $\bullet=$ firm $B$ ).

The other stationary subgame-perfect equilibrium induces a cyclical pricing pattern on the equilibrium path. The symmetric equilibrium strategy and the prices set along the equilibrium path are shown in Figure 2. The firms undercut each other's price successively until the price equals zero and neither firm makes a positive profit. At that price, each firm has an incentive to raise its price. Furthermore, each firm prefers the other firm to raise its price first, so that it can start undercutting in the subsequent period. The probability $\alpha(\delta)$ is determined in such a way that the opponent firm is indifferent between raising and not raising the price. After one firm has raised the price, the undercutting starts again. The price cycles consist of two phases: an undercutting phase and a coordination phase concerning which firm is going to raise the price when the price equals zero. In equilibrium, all prices except 6 are observed.

\subsection{Finite horizon}

Suppose that the time horizon is finite and that future profits are not discounted. We can solve this situation by the application of the backwards induction procedure. ${ }^{4}$ It appears that when the horizon lengthens, the backwards induction outcome does not converge to stationary

\footnotetext{
${ }^{3}$ For proofs see Maskin and Tirole (1988).

${ }^{4}$ Maskin and Tirole (1988) do not consider a finite horizon.
} 


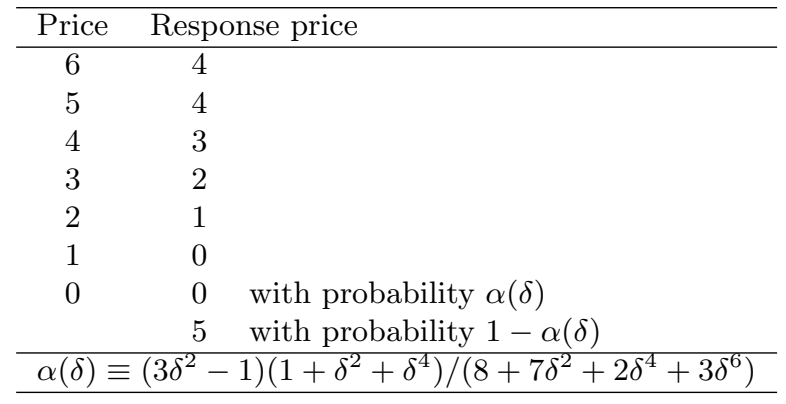

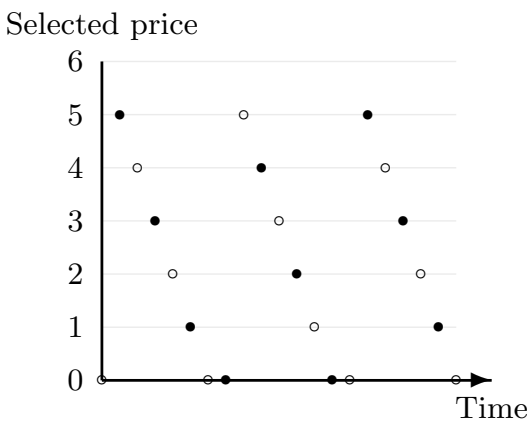

Figure 2: Edgeworth cycle equilibrium. Left panel: symmetric stationary subgame-perfect equilibrium strategy. Right panel: selected price by the respective firm in the respective period $(\circ=$ firm $A ; \bullet=$ firm $B)$.

pricing behavior. In fact, it converges to a pricing pattern that contains recurrent cycles (as long as the final period is not too near). ${ }^{5}$ So, within one cycle, the dynamic response behavior does not only depend on the current price of the opponent, but also on the number of periods that elapsed since the start of the cycle. The non-stationary cyclical pricing behavior to which the backwards induction outcome converges is illustrated in Figure 3.
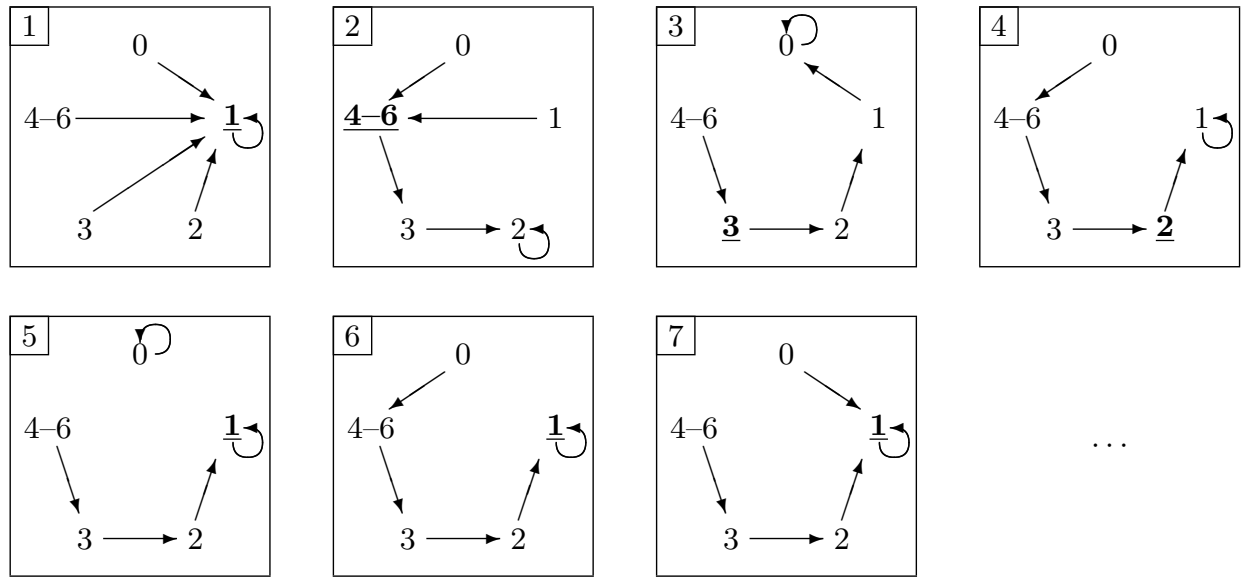

Figure 3: Best responses for long finite horizons.

In total each cycle has a length of seven periods and the two firms start a new cycle in alternating turns. The seven boxes in the figure represent these seven periods (numbered 1 to 7). The arrows indicate the dynamic response to each possible price the opponent may be committed to. In each box, the price that will be realized along the equilibrium path (if the horizon is sufficiently lengthy) is underlined and shown in boldface.

In box 1, regardless of the opponent's current price, the adapting firm sets its price at 1. This means that once, in the course of play, this dynamic response behavior is reached a price equal to 1 is guaranteed to be realized (and therefore makes this box the most convenient one to start with in the explanation of the cycle). Next, in box 2, the price of 1 is responded with one of the prices 4,5 and 6 . By overshooting the current market price, the opponent foregoes

\footnotetext{
${ }^{5}$ See Appendix $\mathrm{C}$ for the used Mathematica code to solve for the backwards induction outcome.
} 
any immediate profit in exchange for future profits. In box 3 , no matter which of the three prices were chosen in box 2 , the response is to undercut this price by setting the price equal to 3 (such that in the previous box the opponent is indeed indifferent between setting a price of 4,5 , or 6 ). Thereby the maximum immediate profit of 9 is gained. Next, in box 4 , the opponent undercuts this price by setting its price equal to 2 , and this price is again undercut by a price of 1 in box 5 . Then, the price remains at 1 in box 6,7 and 1 in order to be brought up in box 2 and subsequently to start the gradual undercutting. A graphical illustration of the cycle of realized prices is given in Figure 4. Notice that the figure may not contain prices observed in initial periods and does not contain prices that are observed when the horizon is near.

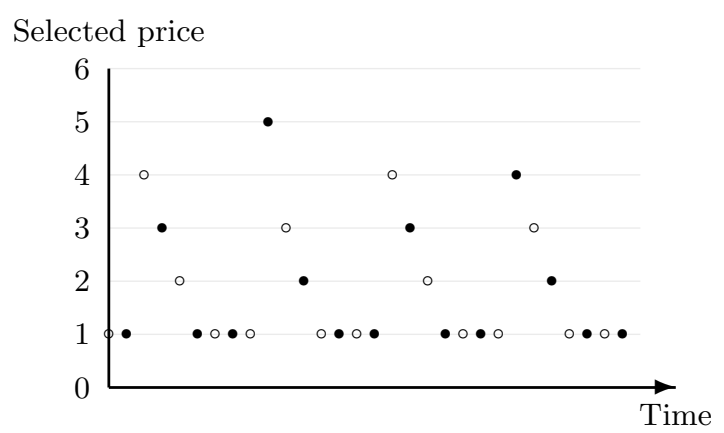

Figure 4: Cyclical pattern of selected prices $(\bullet=$ firm 1 ; ० = firm 2).

\section{$3 \quad$ Experimental design and procedures}

In our experiment, we study pricing behavior in four different treatments that vary in two different dimensions. The first dimension considers the presence of short-run price commitments, which results in treatments with simultaneous moves and treatments with alternating moves. The second dimension considers the time horizon that either may be finite but lengthy (with a fixed ending) or infinite (with a random ending). The resulting two-by-two design is summarized in Table 2.

\begin{tabular}{lcc}
\hline & Random ending & Fixed ending \\
\hline Simultaneous moves & $\mathrm{SR} / 14 / 67$ & $\mathrm{SF} / 15 / 80$ \\
Alternating moves & $\mathrm{AR} / 15 / 67$ & $\mathrm{AF} / 15 / 80$ \\
\hline
\end{tabular}

Table 2: The two-by-two design. The information in the cells refer subsequently to the used abbreviation for the treatment, the number of independent observations for the respective treatment, and the number of rounds each pair of subjects played in the respective treatment.

For the treatments with random ending, in each period there was a two percent probability that the experiment ended after that period. Before the experiment was conducted we generated a sequence of numbers between 0 and 1 according to a uniform distribution. The first draw that led to a number below 0.02 determined the number of rounds that was used for 
all subjects in all treatments with random ending. This number turned out to be 67 , such that the treatments with random ending consisted of 67 periods. In the treatment with fixed ending, the experiment ended after 80 periods. ${ }^{6}$ In all treatments, subjects were perfectly informed about the determination of the number of periods.

At the beginning of the session, subjects were randomly matched in pairs and it was common knowledge that the matching did not change throughout the experiment. Subjects, however, never learned the identity of the subject they were matched with. For the treatments with alternating moves, the experiment started with a pre-stage phase in which both subjects simultaneously had to set an initial price. Next, for each matched pair of subjects, it was randomly decided which of the two subjects could adapt the price in the first period. In the first period, this subject responded to the other's price set in the pre-stage phase. ${ }^{7}$

Every period, the subjects that were able to adapt their prices could do so by marking one of the seven possible prices. In the treatments with alternating moves, the price of the temporarily committed opponent was displayed on the screen of the subjects that were able to adapt their price. At the end of each period, all subjects received an overview of the results of that period, which consisted of both prices, own profit, and own total profit so far.

The experiment was conducted in the behavioral and experimental laboratory (BeeLab) of the Faculty of Economics and Business Administration at Maastricht University in November 2007 (alternating move treatments) and September 2008 (simultaneous move treatments). The laboratory has a capacity of 32 students and we allowed precisely 32 students to register for each of the three sessions. The experiment was announced via email and subjects could register online using their matriculation number, which ensured that students could participate only once. When students arrived at the laboratory, they had to draw a card from a deck that determined at which computer terminal they were placed. In case an odd number of students showed up for a session, we included a blank card in the deck. Students that drew the blank card could not participate and were paid $€$ 5.- as compensation. In total, 118 undergraduate students participated in the experiment. Students not showing up or cancelling on short notice led only to a small imbalance in the number of independent observations.

All interactions took place via computers that were connected to a network and the computer terminals were placed in such a way that subjects could neither see the screens of others nor make eye contact with them. The experiment was programmed and conducted with the software z-Tree (Fischbacher, 2007). Before the start of a session, subjects read the instructions and were allowed to privately ask questions that were then privately answered. After reading the instructions, subjects had to answer control questions, which tested their understanding of the instructions. ${ }^{8}$ One of the experimenters checked the answers, and the experiment only started after all subjects answered each question correctly. During the ex-

\footnotetext{
${ }^{6} \mathrm{~A}$ horizon of 50 periods would coincide with the ex ante expected length of the random ending treatment. However, it would make the treatments only more balanced in the first period where behavior has not matured yet.

${ }^{7}$ The pre-stage price of the subject that could adapt its price in the first period was never revealed.

${ }^{8}$ See Appendix B for the instructions and control questions.
} 
periment, subjects earned ECU that were converted into Euros at a known exchange rate at the end of the experiment. We used the same exchange rates in both treatments and 20 ECU was exchanged for 1 Euro. The average payoff was $€ 19.45$ including a show-up fee of $€ 5$.-. Sessions lasted, depending on the treatment, between 60 and 75 minutes. Payment took place privately, and subjects had to leave the laboratory immediately after payment.

\section{Collusion and price dynamics}

The figures in Appendix A present all data that were retrieved throughout the experimental sessions. In this section we provide an analysis of these data. In particular, we will investigate whether short-run price commitments facilitate collusion and lead to more price stability. In the analysis we neglect premature decision-making in all treatments by excluding all pricing decisions in the first fourteen periods. Moreover, we neglect end-game effects in the treatments with fixed ending by excluding the decisions made in the last six periods of these treatments. Hence, all results reported in this section are based on the decisions between periods 15 and 67 for the treatments with random ending and the decisions between periods 15 and 74 for the treatments with fixed ending. The inclusion or exclusion of additional periods does not lead to different conclusions.

\subsection{Collusion}

In settings where firms (subjects) interact repeatedly, decisions in one period -when perfectly observable- can serve as a signal of intensions in later periods. Thereby repetition provides a communication device to achieve cooperative behavior. In presence of short-run price commitments, the price set in one period will remain unchanged in the next period. Therefore it serves as a credible signal of intensions regarding the aggressiveness of play in the next period, and possibly future periods. Hence, in the treatments with alternating moves, it should be easier for subjects to coordinate on a collusive outcome than in the treatments with simultaneous moves.

Hypothesis 1. Short-run price commitments facilitate collusive behavior.

Here, collusive behavior is generally characterized and hence can be recognized by larger aggregate profit levels. ${ }^{9}$ For each independent observation (a pair of matched subjects) in each treatment we calculated the average per-period joint profit. With these independent observations we test the null hypothesis that profits are equal against the alternative hypothesis that they are unequal. Since the data is unpaired and the alternative hypothesis undirected,

\footnotetext{
${ }^{9}$ Notice that, in (stationary) subgame-perfect equilibrium, expected profits are larger for the treatments with alternating moves. Therefore, the word 'collusion' should be taken with care. Still, the profits obtained in the experimental sessions, that are reported below, are above the equilibrium predictions, apart from the focal point equilibrium for the treatment with alternating moves and random ending. This provides some justification for the use of the word 'collusion', although the difference between equilibrium profits renders a fair quantitative comparison more difficult.
} 
we apply two-sided Mann-Whitney tests to compare profit levels between different pairs of treatments. Table 3 presents the average over these per-period pair-profits for each of the four treatments and the $p$-values of the relevant treatment comparisons.

\begin{tabular}{lccc}
\hline & \multicolumn{2}{c}{ Random ending } & \multicolumn{2}{c}{ Fixed ending } \\
\hline Simultaneous moves & 7.3801 & {$[0.1355]$} & 8.1789 \\
& {$[0.0334]$} & & {$[0.5591]$} \\
Alternating moves & 8.4403 & {$[0.1763]$} & 7.8667 \\
\hline
\end{tabular}

Table 3: Average per-period pair-profit. Between square brackets, the $p$-values of the two-sided MannWhitney test (tie-adjusted) comparing the profit levels in the different treatments are displayed.

We find that in case of a random ending, the treatment with alternating moves generated a significantly larger profit than the treatment with simultaneous moves. However, a similar ranking is not found among the treatments with fixed ending. There, though insignificant, the average per-period profit is even larger for the treatment with simultaneous moves. Among the two treatments with simultaneous moves, the one with fixed ending has generated a larger profit than the one with random ending. For the treatments with alternating moves, the opposite ranking is found between the two treatments. These latter two observations are, however, insignificant.

Result 1. Alternating moves generate larger profits in the case of a random ending. For fixed ending there is no significant difference in the profits generated.

This result provides support for our hypothesis only in case of a random ending. This indicates that for settings with an infinite time horizon, short-run price commitments facilitate collusion. But, when there is a clear ending, short-run price commitments have no significant impact on cooperation.

\subsection{Price dynamics: stability}

In this subsection, we focus on the dynamics of the price that are set. Given the theoretical predictions of the (stationary) subgame-perfect equilibrium outcomes, for treatments with simultaneous moves, prices are expected to fluctuate between 0 and 1. By application of weak selection criteria, a constant price at 1 is more likely to be observed in these treatments. In both treatments with alternating moves, price cycles can occur on the equilibrium path. This price cycle follows the typical rocket-feather pricing pattern, where a series of small price decrements is followed by a sudden substantial increment, after which the process of undercutting resumes, possibly after a period of stable prices. For the fixed ending this is the only prediction, but for the random ending there is a second equilibrium that predicts prices to be constant at 3 . So, if at all, price cycles are only observed in the treatments with alternating moves.

We first focus on the stability of the prices. More precise, the remaining of this subsection is devoted to study the following hypothesis. 


\section{Hypothesis 2. Short-run price commitments facilitate price instability.}

In order to test this hypothesis we need a measure to assess the price stability for any given observation. As measure we will use the likelihood probability that a price is matched, and call this probability the measure of stickiness. ${ }^{10}$ This measure is determined as follows. First, we take as state space $S$ the prices that have been chosen at least once during the course of play. Then, for any pair of prices $\left(s, s^{\prime}\right)$ in this state space, we determine the conditional switching probability $q\left(s, s^{\prime}\right)=\operatorname{Pr}\left(p_{t+1}^{i}=s^{\prime} \mid p_{t}^{-i}=s\right)$. That is, the probability that price $s$ chosen by one subject in a certain period is responded with price $s^{\prime}$ by the other subject in the subsequent period. Next, we determine the stationary distribution $\pi_{Q}$ of the Markov process generated by the transition matrix consisting of these conditional switching probabilities $Q=[q(\cdot, \cdot)]$. Finally, we determine the stickiness $\sigma$ of the observation by the likelihood that the process remains in the same state for two consecutive periods. In formulas, $\sigma=\left\langle\pi_{Q}, \operatorname{diag}(Q)\right\rangle=\sum_{s \in S} \pi_{Q}(s) q(s, s)$. This measure takes values between zero and one. A value of zero is reached if the process has the property that no state is ever visited in two consecutive periods. A value of one is reached in case there is a single absorbing state. Now, price instability can be recognized by a low value of $\sigma$.

Table 4 presents for each of the different groups in the different treatments the measure of stickiness. There are many observations for which a value equal or close to 1 is reported. This

\begin{tabular}{ccccc}
\hline & \multicolumn{4}{c}{ Treatment } \\
\cline { 2 - 5 } Group & SR & SF & AR & AF \\
\hline 1 & 0.8491 & 0.9832 & 1.0000 & 1.0000 \\
2 & 1.0000 & 1.0000 & 1.0000 & 0.4262 \\
3 & 0.5494 & 1.0000 & 1.0000 & 1.0000 \\
4 & 1.0000 & 0.8500 & 1.0000 & 1.0000 \\
5 & 1.0000 & 0.9833 & 1.0000 & 1.0000 \\
6 & 1.0000 & 0.9834 & 0.6170 & 0.9667 \\
7 & 0.3134 & 1.0000 & 1.0000 & 0.6891 \\
8 & 0.8826 & 0.8550 & 1.0000 & 0.6065 \\
9 & 0.9798 & 0.9037 & 0.9616 & 0.3220 \\
10 & 0.7244 & 1.0000 & 0.8808 & 0.1833 \\
11 & 1.0000 & 0.8856 & 1.0000 & 1.0000 \\
12 & 0.7641 & 1.0000 & 1.0000 & 0.9551 \\
13 & 0.6573 & 1.0000 & 0.8231 & 0.8637 \\
14 & 0.6348 & 1.0000 & 1.0000 & 1.0000 \\
15 & & 0.9095 & 1.0000 & 1.0000 \\
\hline
\end{tabular}

Table 4: Measure of stickiness for all groups in each treatment.

indicates that many pairs were able to coordinate on a joint price (though not necessarily at price level 3). We use the values in this table to test the null hypothesis that the measures

\footnotetext{
${ }^{10}$ Although the measure is rather natural, we are not aware of the existence of an eventual conventional name for it.
} 
of stickiness are equal against the alternative hypothesis that they are unequal for each pair of comparable treatments. Like for the profits in the previous subsection, we apply two-sided Mann-Whitney tests. Table 5 presents the average measure of stickiness for each of the four treatments and the $p$-values of the relevant treatment comparisons.

\begin{tabular}{lccc}
\hline & \multicolumn{2}{c}{ Random ending } & \multicolumn{2}{c}{ Fixed ending } \\
\hline Simultaneous moves & 0.8111 & {$[0.0668]$} & 0.9569 \\
& {$[0.0334]$} & & {$[0.3816]$} \\
Alternating moves & 0.9522 & {$[0.0918]$} & 0.8008 \\
\hline
\end{tabular}

Table 5: Average stickiness of price dynamics. Between square brackets, the $p$-values of the two-sided Mann-Whitney test (tie-adjusted) comparing the level of stickiness in the different treatments are displayed.

We find that in case of a random ending, alternating moves generate significantly more price stickiness than simultaneous moves. A similar ranking among treatments is however not found for the treatments with fixed ending; if anything, though far from significant, even the opposite ranking is found. Among the two treatments with simultaneous moves, the one with fixed ending generates more price stickiness than the one with random ending. For the treatments with alternating moves, the opposite ranking among ending properties is found.

Result 2. Alternating moves generate more price stickiness in the case of a random ending. For fixed ending no significant difference is found. For simultaneous (alternating) moves a fixed ending generates more (less) price stickiness than a random ending.

This results provides support against our hypothesis that short-run price commitments facilitate price instability. For the random ending we even find that short-run price commitments enhance price stability. For the fixed ending any possible impact of short-run price commitments on price stability is insignificant.

\subsection{Price dynamics: cycles}

Finally, we investigate whether prices cycle. Our last hypothesis is formulated in accordance with the theoretical predictions.

Hypothesis 3. Short-run price commitments enhance cyclical price dynamics.

In order to investigate this hypothesis, we need a characterization of a price cycle that follows the typical the rocket-feather pattern. Such a cycle can be characterized by several properties. First, there are multiple price levels that are frequently and recurrently observed. This is the case if and only if the measure of stickiness is strictly less than one (that is, when there is no absorbing state). Next, price undercuts should go in small steps with high probability. This property can be identified by a rather high conditional probability that $p_{t}^{i}=p_{t-1}^{-i}-1$ for prices $p_{t-1}^{-i}$ above the bottom of the price cycle. Finally, price increases go in larger steps and occur with a smaller probability. This indicates that we should observe more price decrements than 
increments in our data. Furthermore, periods of price stability can only be observed at the bottom of the price cycle, which is identified with a non-negligible conditional probability that $p_{t}^{i}=p_{t-1}^{-i}$ at the bottom. ${ }^{11}$

Qualitatively these conditions for a price cycle are rather indisputable. However, in order to implement these conditions for practical purposes, a quantification of terms like 'small' and 'large' is needed. Table 6 contains a classification of the different observations, for which we used the following quantification of the conditions. ${ }^{12}$ First, a price pattern is classified as constant as soon as the measure of stickiness is above 0.75 and the stationary distribution of the conditional switching probabilities assigns a weight larger than 0.65 to a certain price level. Second, for a cycle there should be an interval of prices (containing at least two prices) for which each price within this interval has weight larger than 0.10 in the stationary distribution. This ensures that in a cycle undercuts go with small steps and that each price that is in the support of the cycle is observed at least every tenth period. Moreover, the expected probability of a weak (strict) undercut at prices above the lowest price in this interval should exceed 0.60 (0.20), and the probability of a strict overshoot at the lowest price should exceed 0.10. This ensures that there is sufficient instability at the bottom of the price cycle and a decreasing price trend as long as the bottom price has not yet been reached. Finally, the remaining observations are classified neither as a constant price nor as a price cycle.

\begin{tabular}{|c|c|c|c|c|}
\hline & \multicolumn{4}{|c|}{ Treatment } \\
\hline & SR & $\mathrm{SF}$ & $\mathrm{AR}$ & $\mathrm{AF}$ \\
\hline cycle & $7,10,13-14$ & & 6 & $2,7-10$ \\
\hline constant at 1 & 1 & 4,6 & & \\
\hline$\longrightarrow$ at 2 & 12 & & 15 & 13 \\
\hline $\begin{array}{l}\text { ather } \\
\text { oth }\end{array}$ & $\begin{array}{c}2,4-6,8-9,11 \\
3\end{array}$ & $\begin{array}{c}1-3,5,7-10,12-15 \\
11\end{array}$ & $1-5,7-14$ & $1,3-6,11-12,14-15$ \\
\hline
\end{tabular}

Table 6: Classification of groups on basis of the observed pricing pattern.

In line with the high measures of stickiness observed in the previous subsection, in each treatment the majority of the observations are classified as constant. This holds in particularly for the treatments SF and AR, where apart from one observation all observed pricing patterns are classified as being constant. For the treatments SR and AF, a notable number of price cycles is observed.

\footnotetext{
${ }^{11}$ In empirical studies a negative median price change is sometimes taken as an indication of cycling prices (Lewis, 2006; Doyle et al., 2008). In these studies prices are set on a much finer grid and therefore hardly ever the same in subsequent periods. For the present experiment this is not a suitable classification measure since the coordination stage at the bottom of the cycle can take quite long and hence the median price change will be zero even if prices do cycle. Actually, the median price change equals zero in the backwards induction equilibrium of the finite horizon setting which clearly consists of price cycles. Isaac and Smith (1985) only reject a pricing pattern for being an Edgeworth cycle when there are not multiple price levels that are sufficiently often observed.

${ }^{12}$ The table is rather robust with respect to the precise numbers chosen in the sense that a substantial change in one of the numbers leads to a different classification for at most one or two observations.
} 
Result 3. For simultaneous (alternating) moves a random ending (fixed ending) has more potential to generate price cycles.

The finding that a random ending can cause price cycles when firms set prices simultaneously is in contrast with the (most likely) stationary subgame-perfect equilibrium of constant pricing at price level 1. However, due to the random ending, cycles can be sustainable in equilibrium when trigger strategies are used. This particular support of price cycles would also be applicable in the situation where firms set prices alternately. Though, strong potential for price cycles seems not to be present there. The finding that a fixed ending is more likely to generate a price cycle when firms move alternately is in line with subgame-perfect equilibrium predictions.

\section{Discussion}

Based on the data retrieved throughout a series of experimental sessions, we conclude that in a dynamic homogeneous duopoly where firms set prices repeatedly, short-run price commitments have an increasing impact on firms' profits and lead to more price stability and less price cycles when interaction takes place over an infinite horizon. Where the first effect is in line with the theoretical predictions, the second is not. When the era of strategic interaction is finite, short-run price commitments have no significant impact on behavior and performance.

Various market properties that have been shown to facilitate collusion in experimental markets are present in our setting as well, such as: low market concentration (Dufwenberg and Gneezy, 2000; Huck et al., 2004), constant and certain market conditions (Bereby-Meyer and Roth, 2006), symmetry among firms' characteristics (Mason et al., 1992; Keser, 2000; Fonseca and Normann, 2008), and repeated interaction (Davis and Holt, 1993; Keser, 2000). These characteristics apply to both the treatments with alternating moves as those with simultaneous moves and, hence, do not clarify differences between the two exogenous timing mechanisms. There are, however, two possible aspects that are inherently connected to the alternating-move structure that could explain the difference in performance. The first aspect regards the credible communication channel that is provided by the commitment; the second is the absence of strategic uncertainty.

According to Holt and Davis (1990) and Cason (1995) the possibility to communicate via price announcements facilitates collusion, but the impact fades away during repetitive exposure to the market setting. However, as is shown by Anderson and Wengström (2007), when communication is costly the impact of communication retains. More precisely, they show that costs reduce the amount of communication but enhance the stability of collusive agreements. Apparently costs are needed to make the communication more credible and hence more meaningful. In repeated interactions, like in our setting, actions in earlier rounds can be used to signal the willingness to coordinate on a desirable outcome in future rounds. The signal underneath the chosen action is more credible when firms are committed in the short-run. It is therefore not strange to see more collusion in the treatments with alternating 
moves, though we only find this when the horizon is infinite.

In recent experiments on endogenous timing it has been recognized that many subjects possess some sort of preference for delay. Tykocinski and Ruffle (2003) shows that subjects often delay decisions even when waiting does not provide any additional information. In the strategic contexts of Huck et al. (2002), Müller (2006), and Fonseca et al. (2006), subjects sometimes prefer to wait even when doing so puts them at a strategic disadvantage. One reason to wait is that it may resolve the strategic uncertainty about the opponent's action. Short-run price commitments exterminate the presence of strategic uncertainty. Following this literature, and in line with the theoretical prediction, more price changes are expected to be observed in the treatments with alternating moves. We find, however, exactly the opposite.

Evidence of price cycles in experiments is rather limited. Cason et al. (2005) find that for some variations of the Edgeworth hypothesis ${ }^{13}$, the data of repetitive posted price offers by six sellers displays a cycle. Furthermore, Brown-Kruse et al. (1994) observe price cycles when four players compete while capacity is restricted. Guillén (2004) finds price cycles for an experiment involving simultaneous price and quantity setting in a market with eight competing sellers. However, in the same setting, price cycles are not observed in case of two or three sellers (Brandts and Guillén, 2003). We find that short-run price commitments have the potential to trigger cyclical price patterns in experimental markets, even in case of a duopoly.

\section{References}

1. Anderson $\mathrm{O}$ and E Wengström (2007). Do antitrust laws facilitate collusion? Experimental evidence on costly communication in duopolies. Scandinavian Journal of Economics 109 (2): 321-339.

2. Bereby-Meyer Y and A Roth (2006). The speed of learning in noisy games: partial reinforcement and the sustainability of cooperation. The American Economic Review 96 (4): 1029-1042.

3. Brandts J and P Guillén (2007). Collusion and fights in an experiment with price-setting firms and production in advance. Journal of Industrial Economics 55 (3): 453-473.

4. Brown-Kruse J, S Rassenti, SS Reynolds, and VL Smith (1994). Bertrand-Edgeworth competition in experimental markets. Econometrica 62 (2): 343-371.

5. Cason T (1995). Cheap talk price signaling in laboratory markets. Information Economics and Policy 7 (2): 183-204.

6. Cason T, D Friedman, and F Wagener (2005). The dynamics of price dispersion, or Edgeworth variations. Journal of Economic Dynamics and Control 29 (4): 801-822.

\footnotetext{
${ }^{13}$ This hypothesis states that prices do cycle when firms face capacity constraints and set prices repeatedly (Edgeworth, 1925).
} 
7. Dal Bó P (2005). Cooperation under the shadow of the future: Experimental evidence from infinitely repeated games. The American Economic Review 95 (5): 1591-1604.

8. Davis D and C Holt (1993). Experimental Economics. New Jersey: Princeton University Press.

9. Doyle J, E Muehlegger, and K Samphantharak (2008). Edgeworth cycles revisited. Working paper.

10. Dufwenberg M and U Gneezy (2000). Price competition and market concentration: An experimental study. International Journal of Industrial Organization 18 (1): 7-22.

11. Edgeworth F (1925). The pure theory of monopoly. In: Papers Relating to Political Economy. London: MacMillan. pp. 111-142.

12. Engle-Warnick J and R Slonim (2004). The evolution of strategies in a repeated trust game. Journal of Economic Behavior \& Organization 55 (4): 553-573.

13. Fischbacher U (2007). z-Tree: Zurich toolbox for ready-made economic experiments. Experimental Economics 10 (2): 171-178.

14. Fonseca M, S Huck, and H Normann (2006). Endogenous timing in duopoly: Experimental evidence. International Journal of Game Theory 34 (3): 443-456.

15. Fonseca M and H Normann (2008). Mergers, asymmetries and collusion: Experimental evidence. Economic Journal 118 (527): 387-400.

16. Guillén P (2004). Price-quantity competition and Edgeworth cycles. Working paper, Universitat Autónoma de Barcelona.

17. Holt C and D Davis (1990). The effects of non-binding price announcements on postedoffer markets. Economics Letters 34 (4): 307-310.

18. Huck S, W Müller, and H Normann (2002). To commit or not to commit: Endogenous timing in experimental duopoly markets. Games and Economic Behavior 38 (2): 240264.

19. Huck S, H Normann, and J Oechssler (2004). Two are few and four are many: Number effects in experimental oligopolies. Journal of Economic Behavior \& Organization 53 (4): $435-446$.

20. Isaac R and V Smith (1985). In search of predatory pricing. Journal of Political Economy 93 (2): 320-345.

21. Keser C (2000). Cooperation in symmetric duopolies with demand inertia. International Journal of Industrial Organization 18 (1): 23-38. 
22. Lewis M (2008). Temporary wholesale gasoline price spikes have long-lasting retail effects: The aftermath of hurricane Rita. Journal of Law and Economics: forthcoming.

23. Maskin E and J Tirole (1988). A theory of dynamic oligopoly II: Price competition, kinked demand curves and Edgeworth cycles. Econometrica 56 (3): 571-599.

24. Mason C, O Philipps, and C Nowell (1992). Duopoly behavior in asymmetric markets: An experimental evaluation. Review of Economics and Statistics 74 (4): 662-669.

25. Müller W (2006). Allowing for two production periods in the Cournot duopoly: Experimental Evidence. Journal of Economic Behavior \& Organization 60 (1): 100-111.

26. Normann H and B Wallace (2006). The impact of the termination rule on cooperation in a prisoner's dilemma experiment. Mimeo.

27. Selten R, M Mitzkewitz, and G Uhlich (1997). Duopoly strategies programmed by experienced players. Econometrica 65 (3): 517-555.

28. Selten R and R Stoecker (1986). End behavior in sequences of finite prisoner's dilemma supergames: A learning theory approach. Journal of Economic Behavior \& Organization 7 (1): 47-70.

29. Tykocinski O and B Ruffle (2003). Reasonable reasons for waiting, Journal of Behavioral Decision Making 16 (1): 147-157. 


\section{A Figures}

This appendix contains for each treatment and for each pair of subjects in this treatment a figure that summarizes the prices chosen by these subjects.

\section{A.1 Treatments with simultaneous moves and random ending}

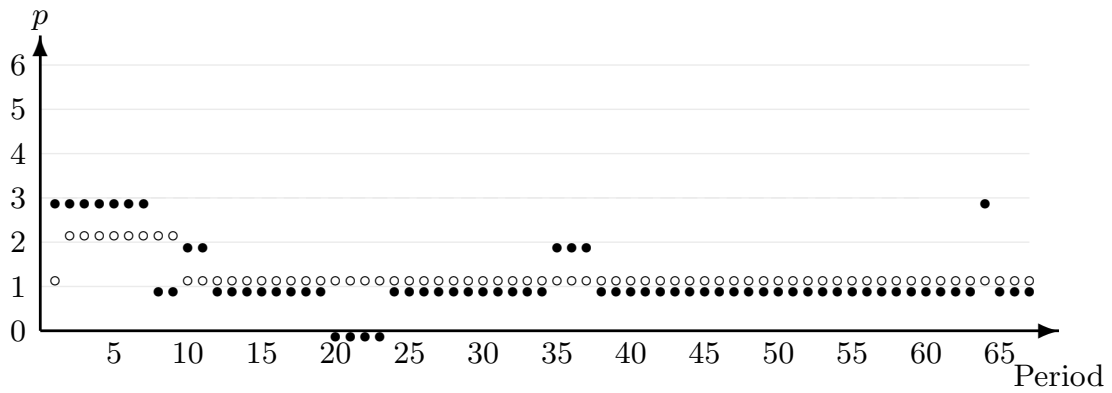

Figure 5: Group SR.1

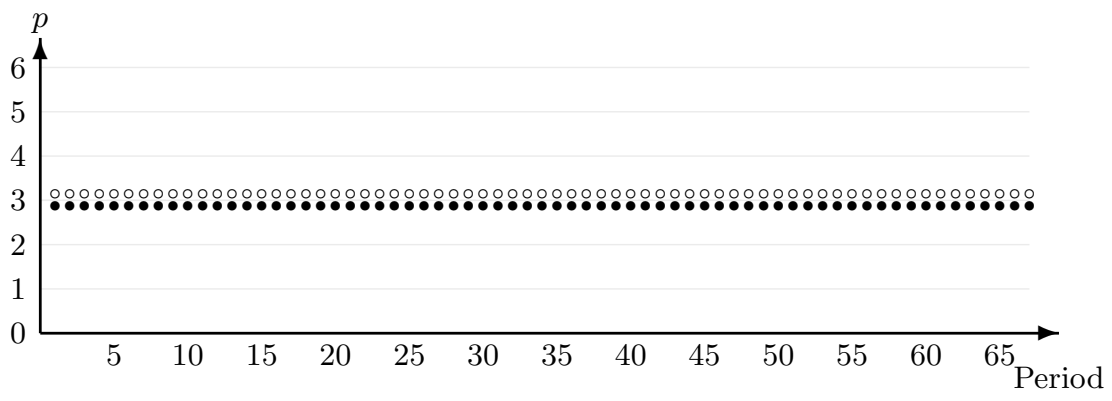

Figure 6: Group SR.2

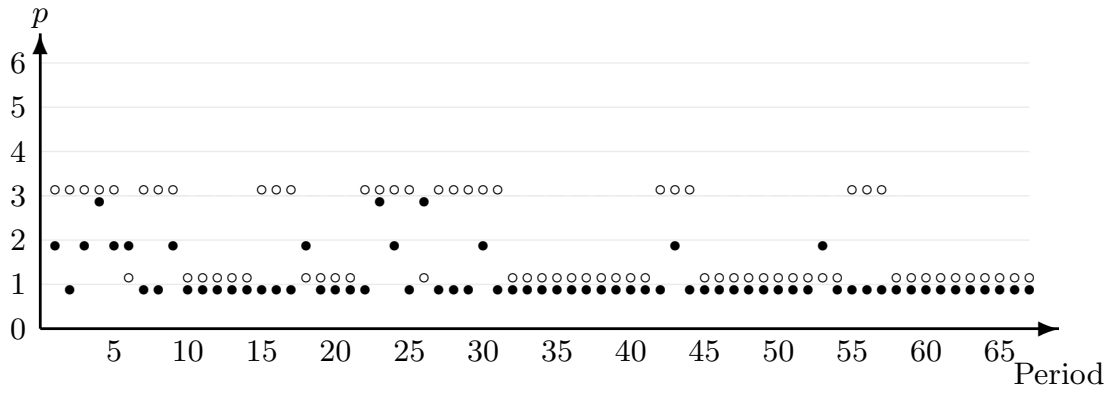

Figure 7: Group SR.3

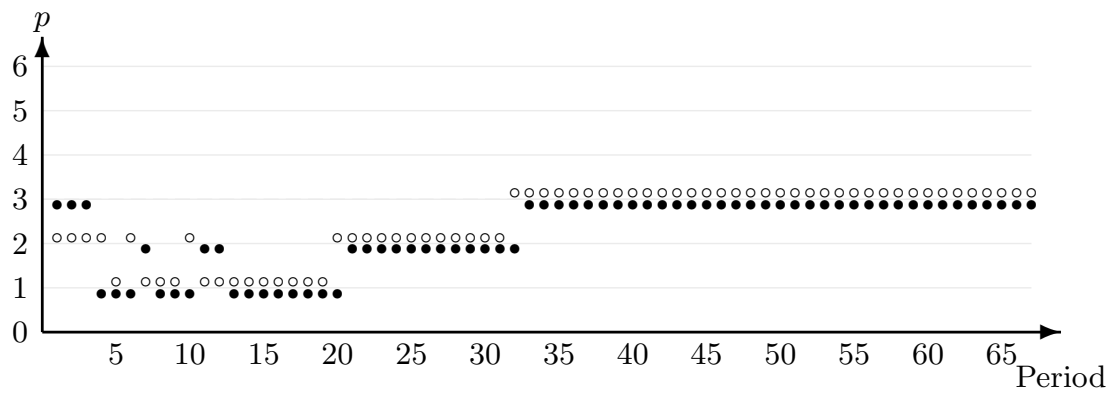

Figure 8: Group SR.4 


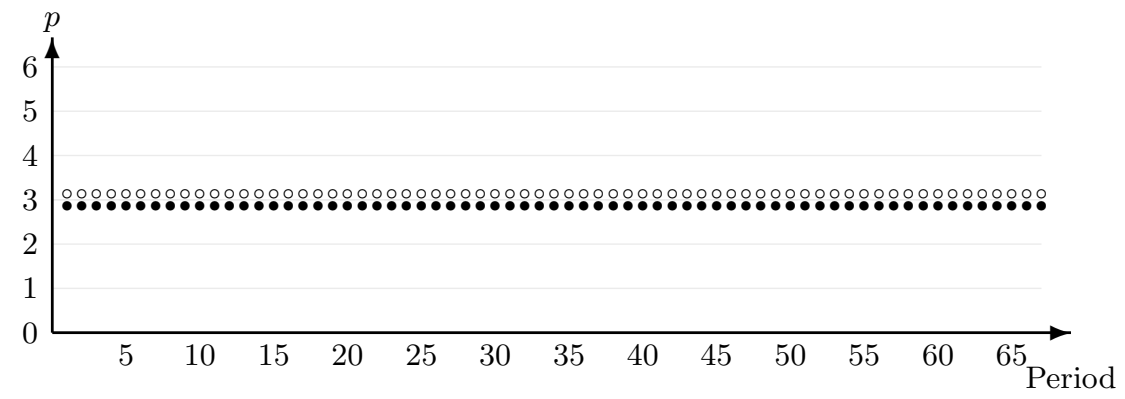

Figure 9: Group SR.5

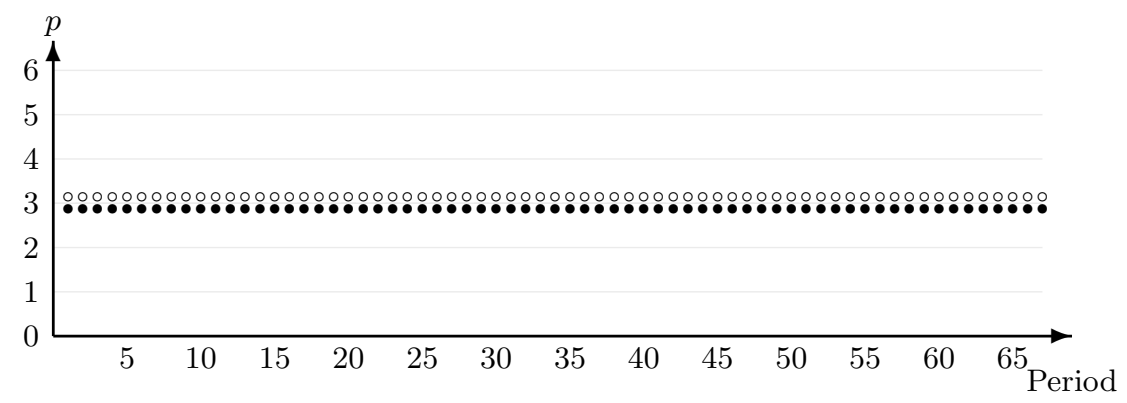

Figure 10: Group SR.6

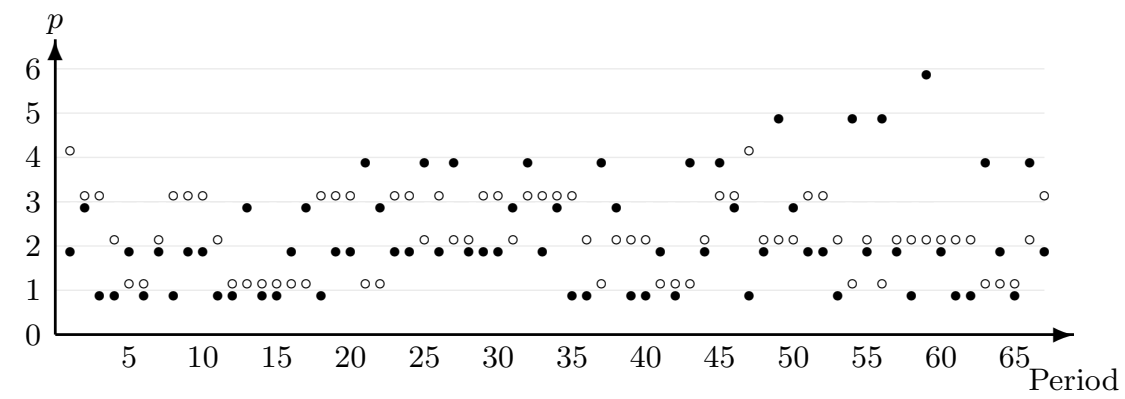

Figure 11: Group SR.7

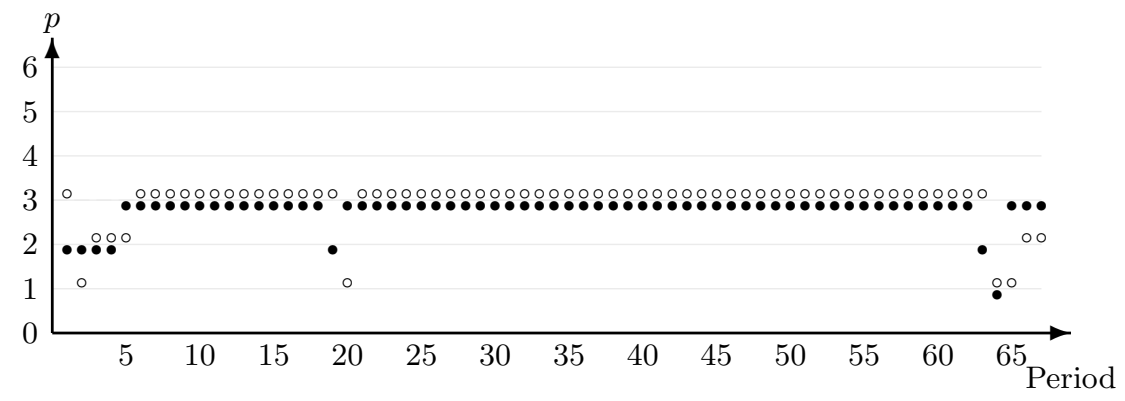

Figure 12: Group SR.8

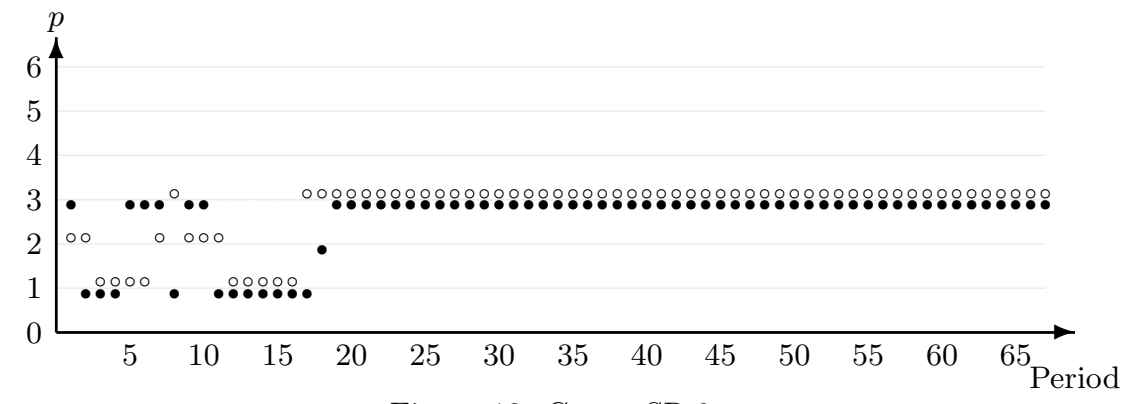

Figure 13: Group SR.9 


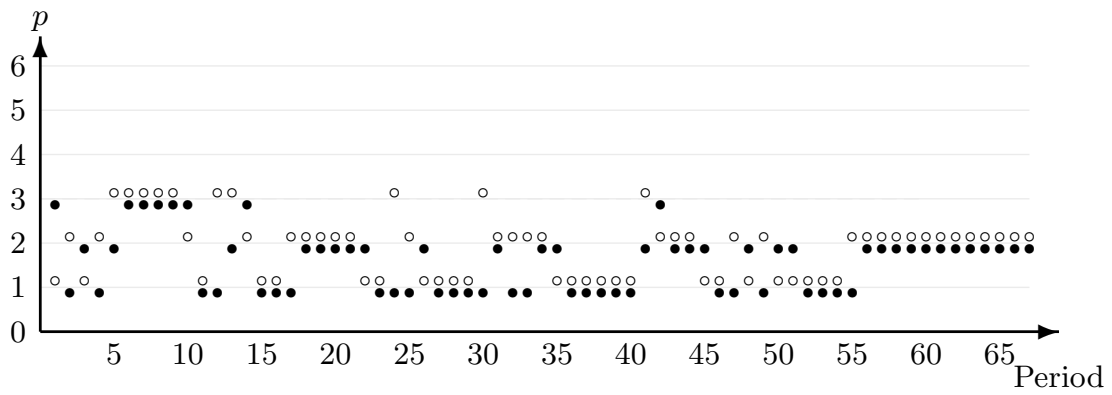

Figure 14: Group SR.10

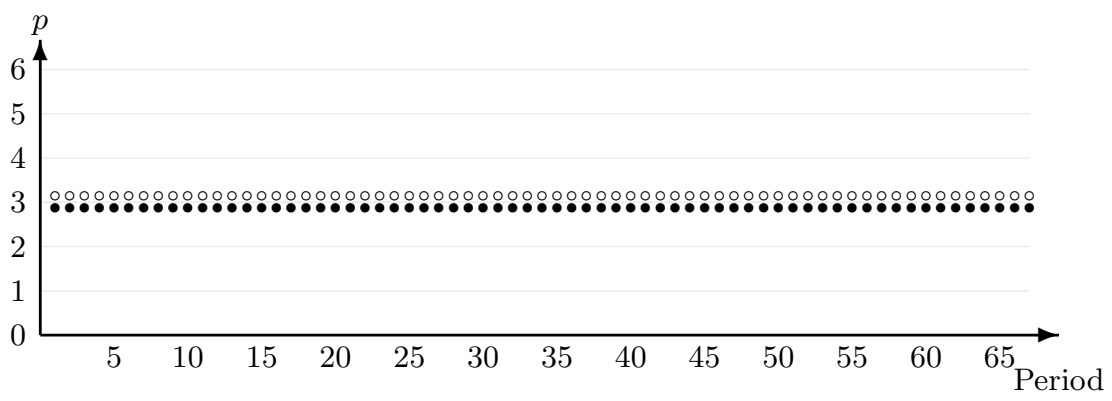

Figure 15: Group SR.11

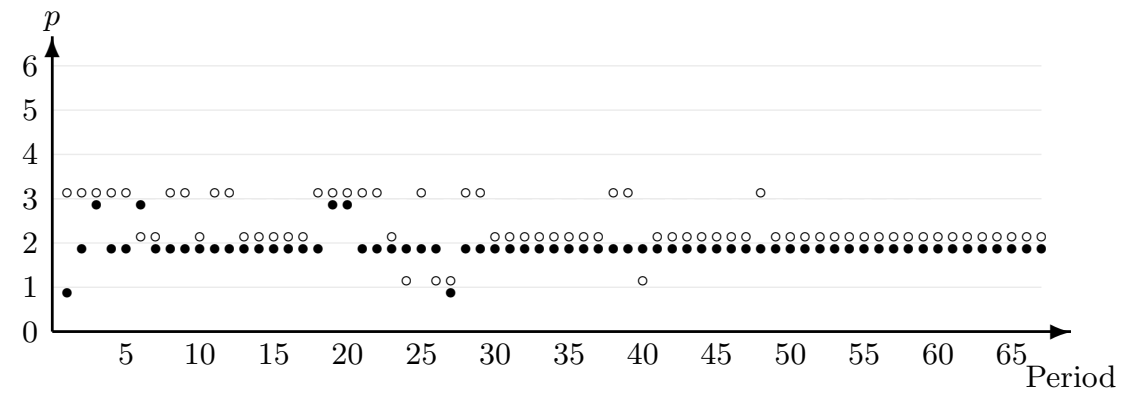

Figure 16: Group SR.12

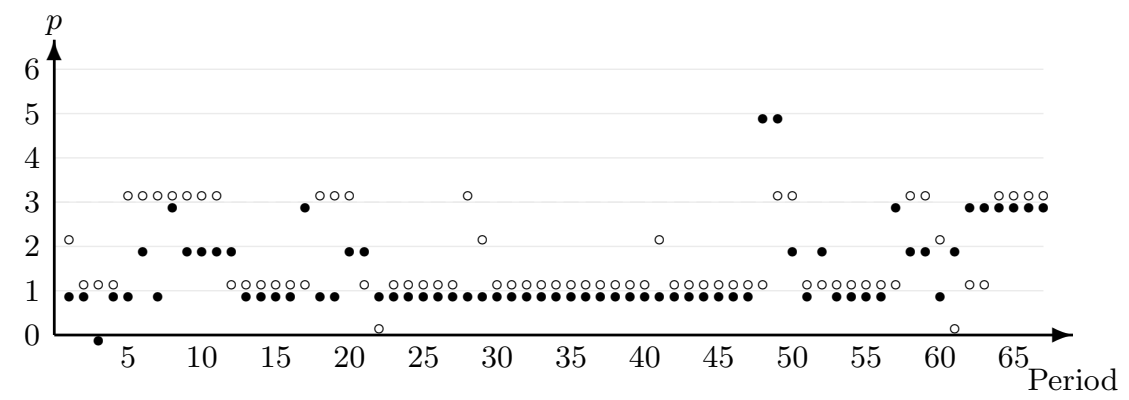

Figure 17: Group SR.13

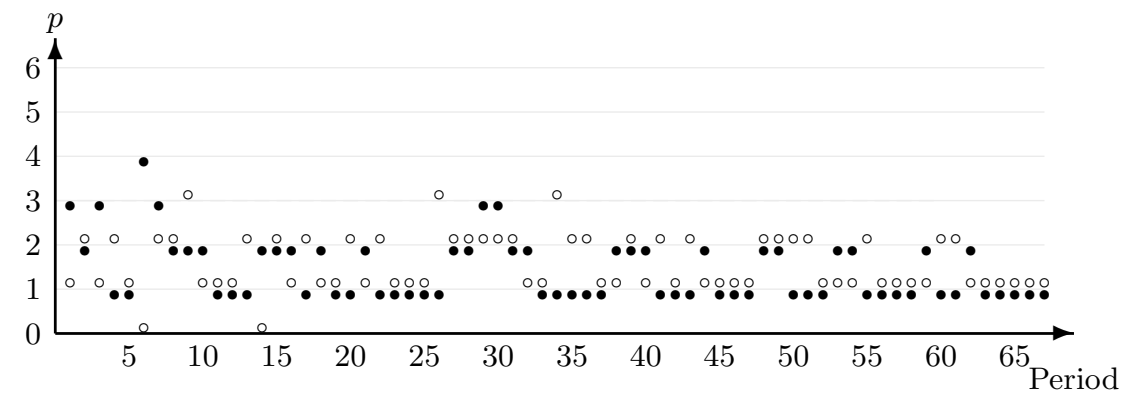

Figure 18: Group SR.14 
A.2 Treatments with simultaneous moves and fixed ending

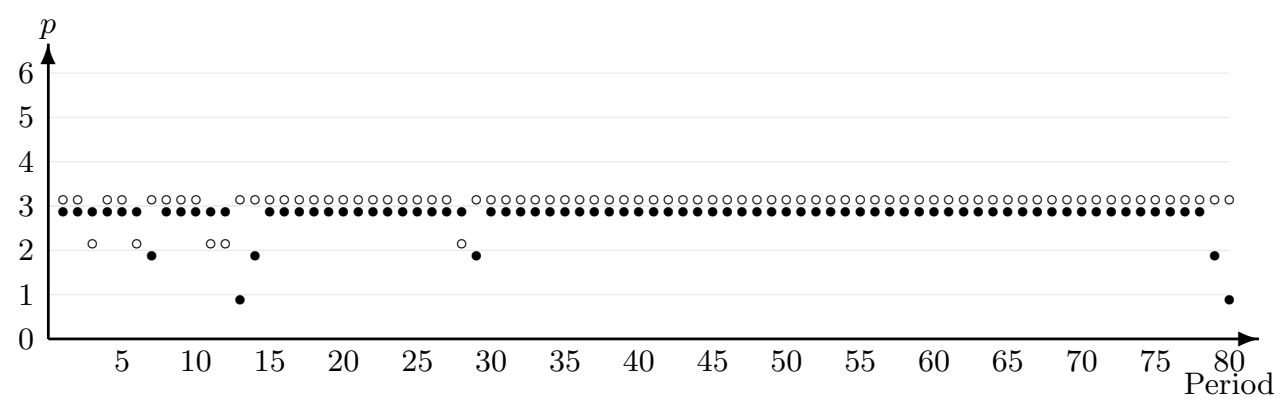

Figure 19: Group SF.1

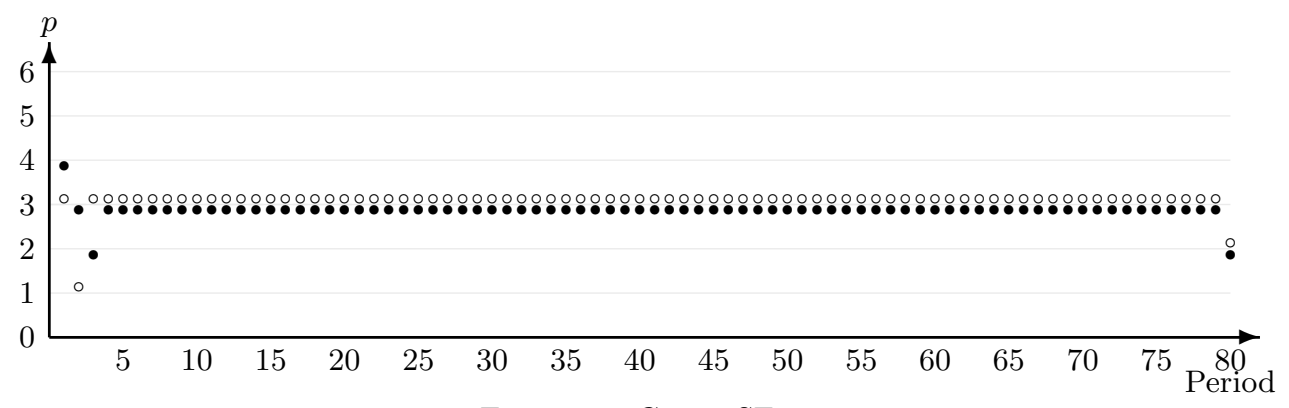

Figure 20: Group SF.2

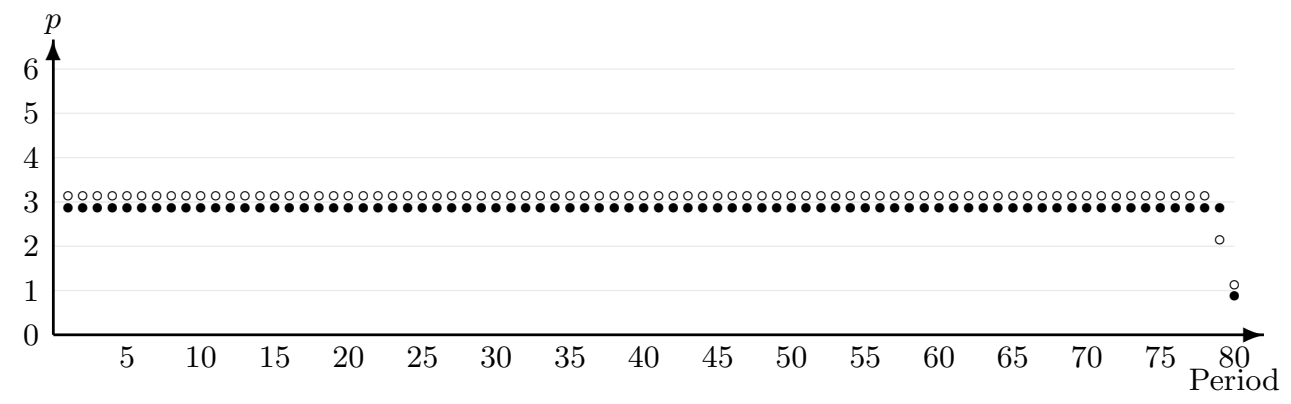

Figure 21: Group SF.3

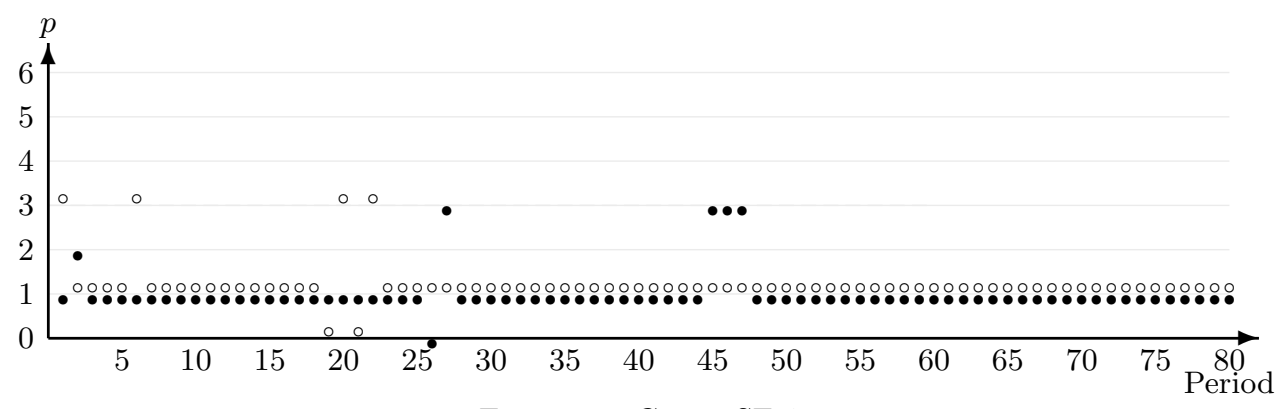

Figure 22: Group SF.4

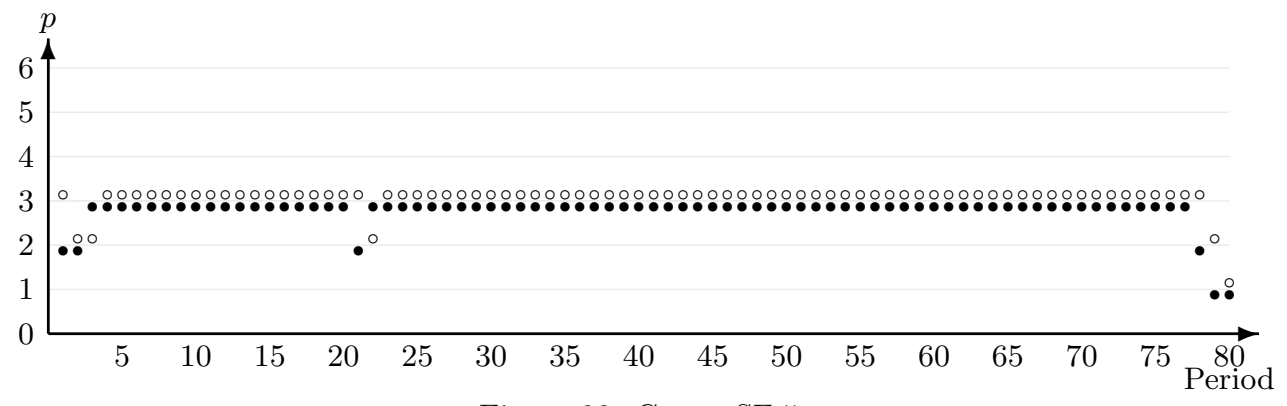

Figure 23: Group SF.5 


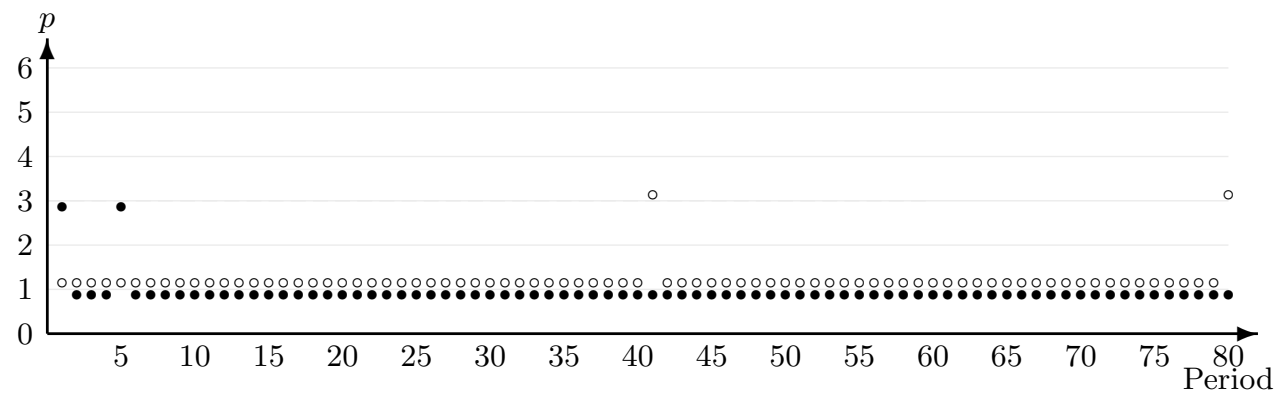

Figure 24: Group SF.6

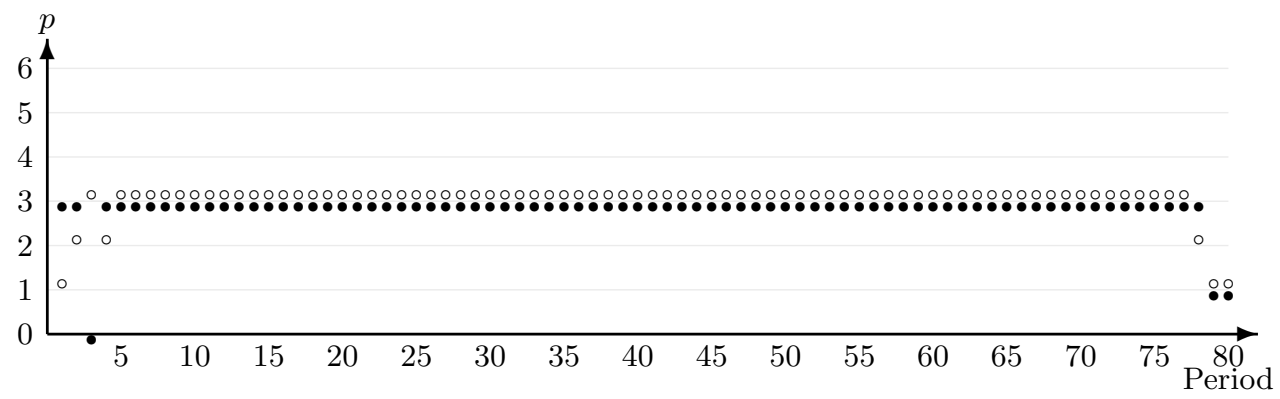

Figure 25: Group SF.7

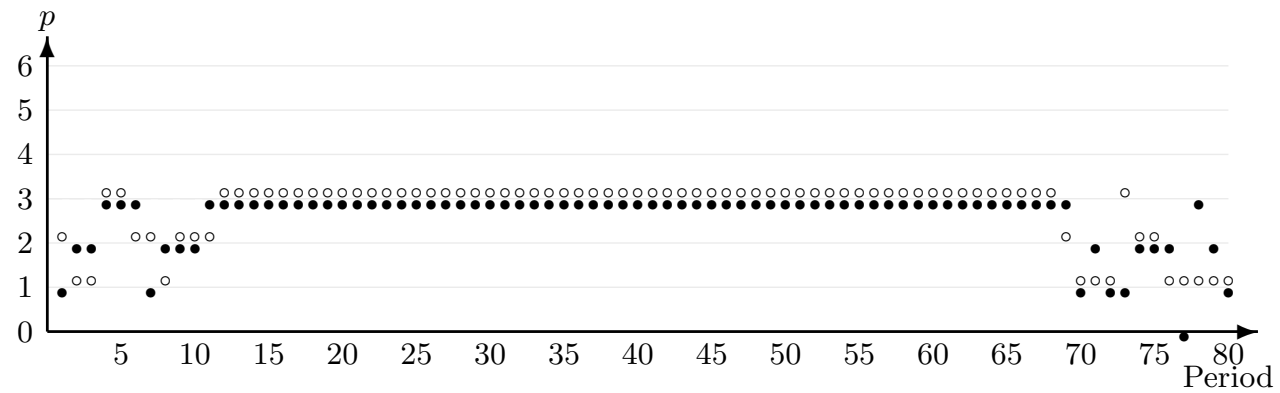

Figure 26: Group SF.8

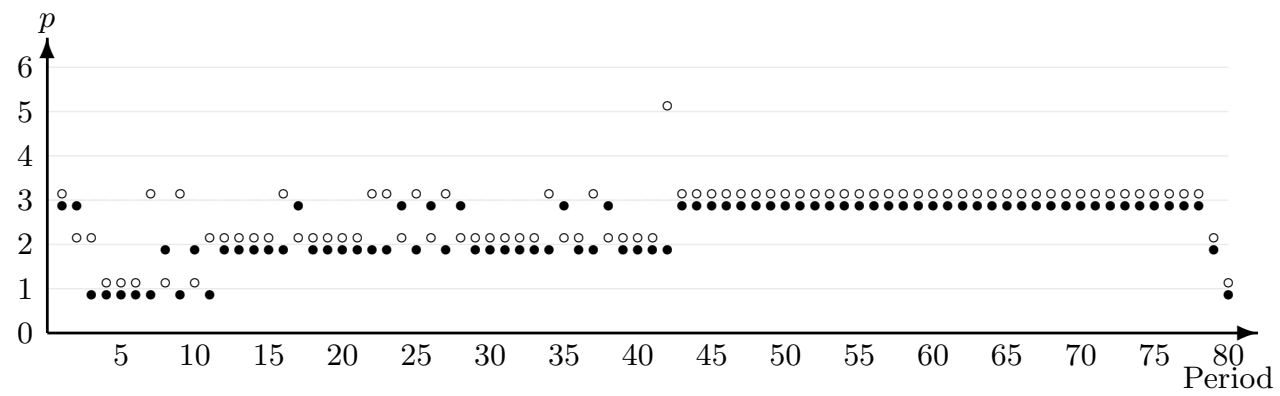

Figure 27: Group SF.9

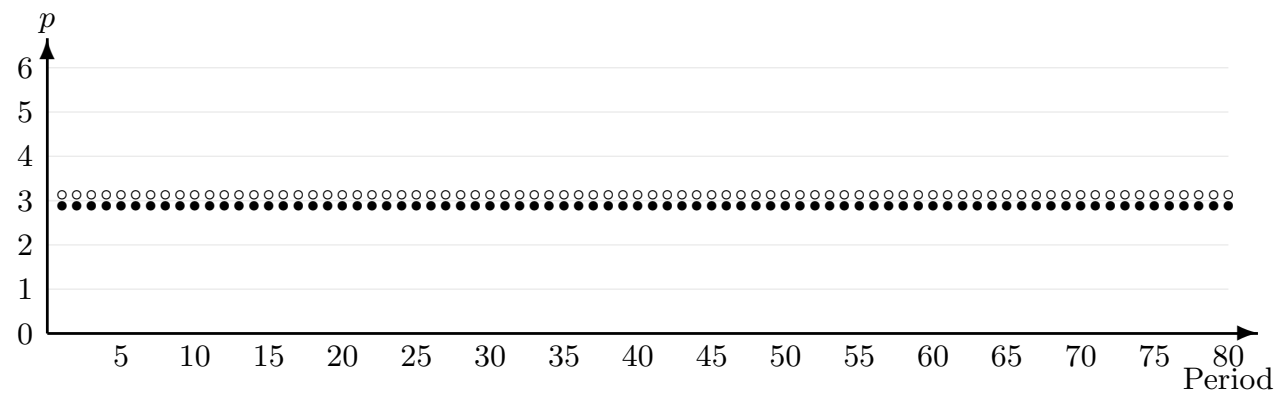

Figure 28: Group SF.10 


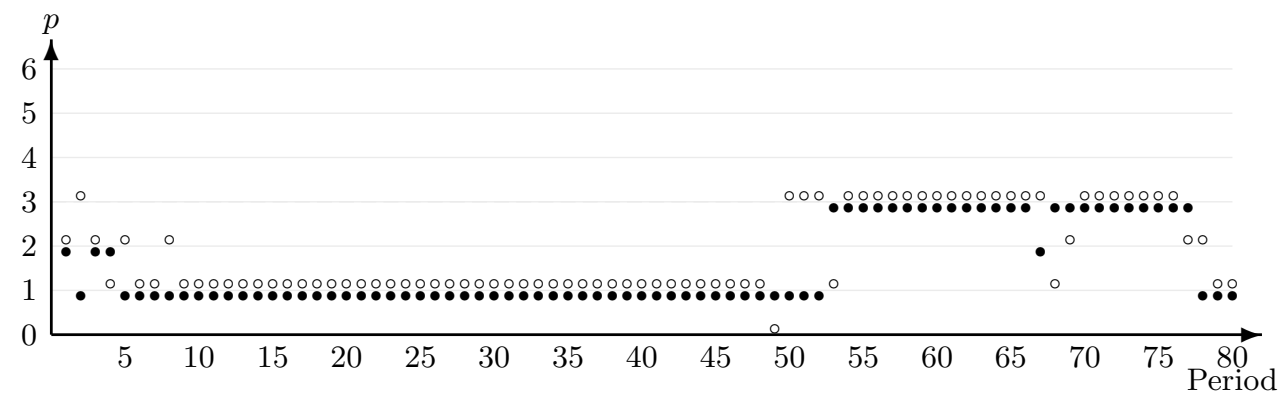

Figure 29: Group SF.11

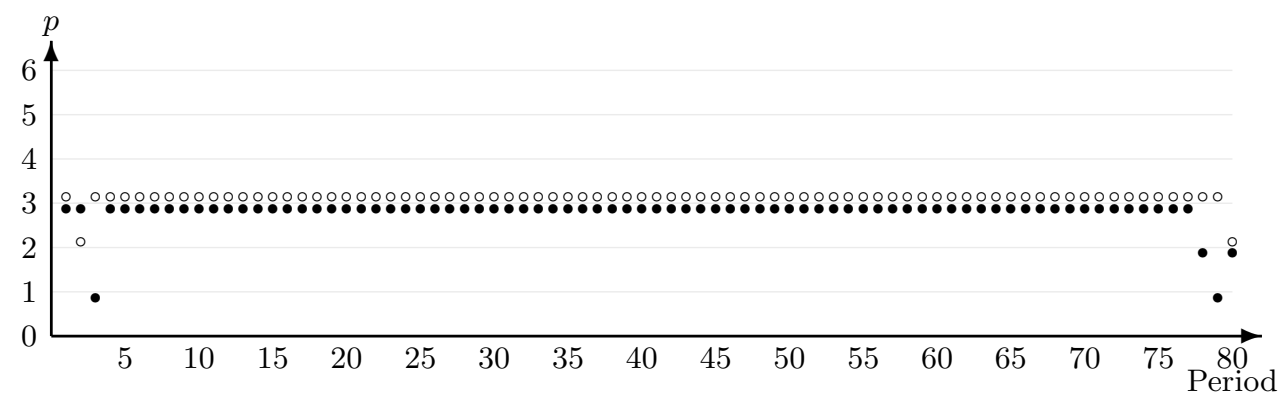

Figure 30: Group SF.12

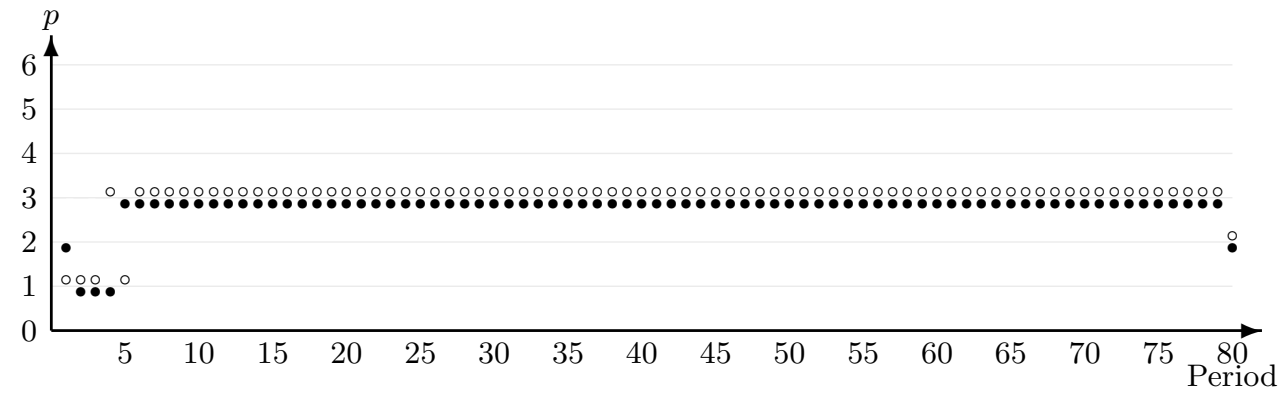

Figure 31: Group SF.13

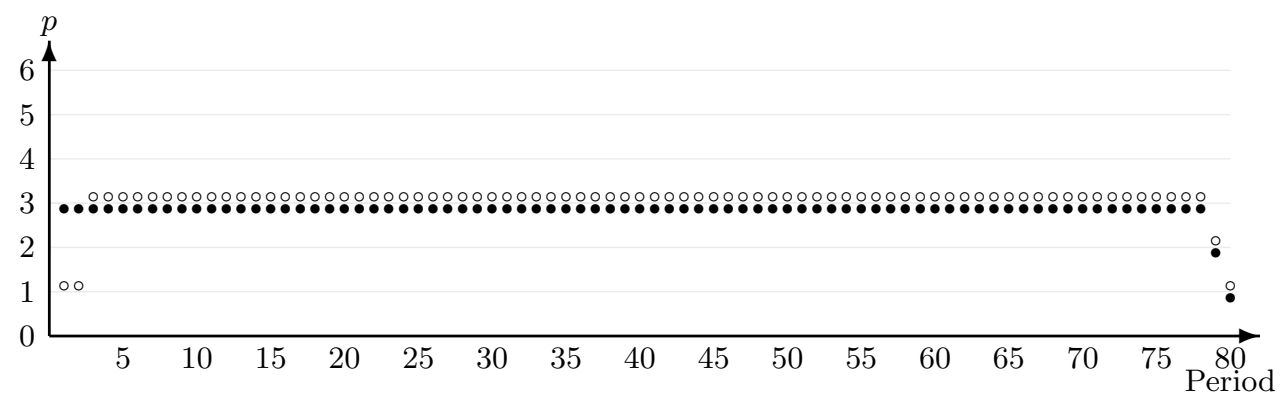

Figure 32: Group SF.14

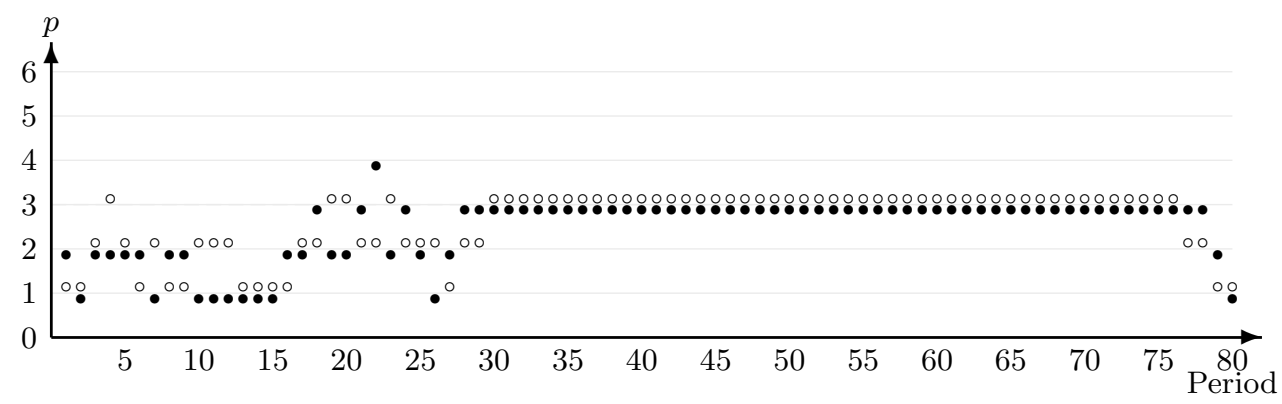

Figure 33: Group SF.15 


\section{A.3 Treatments with alternating moves and random ending}

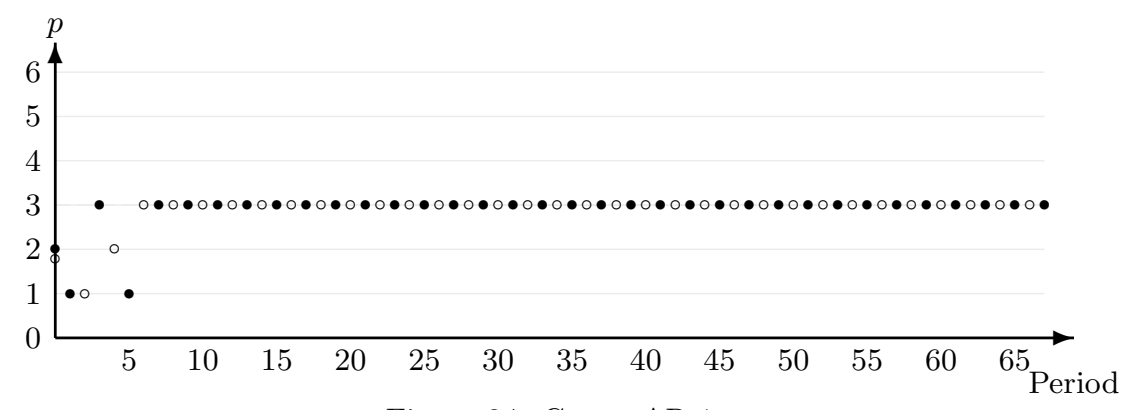

Figure 34: Group AR.1

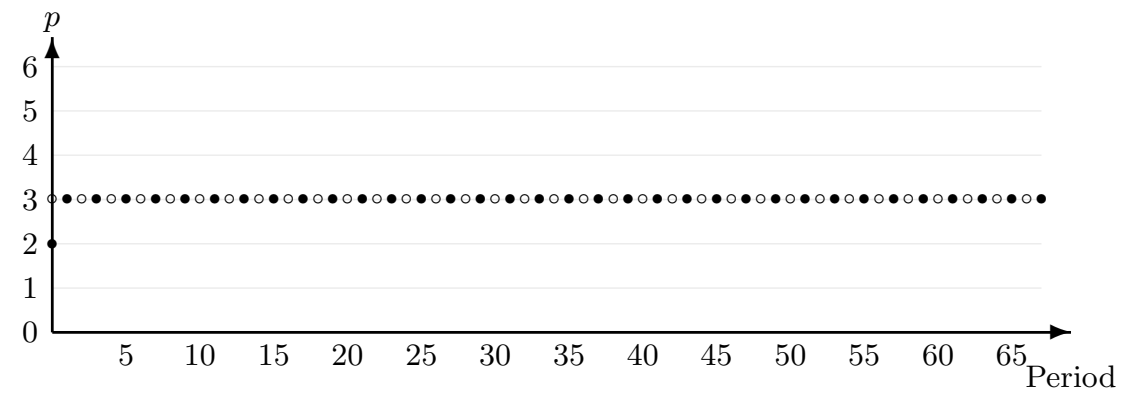

Figure 35: Group AR.2

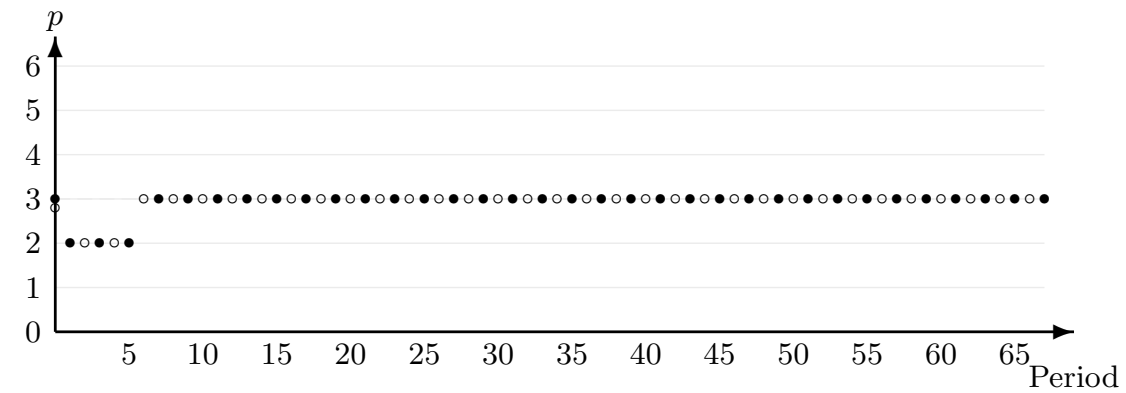

Figure 36: Group AR.3

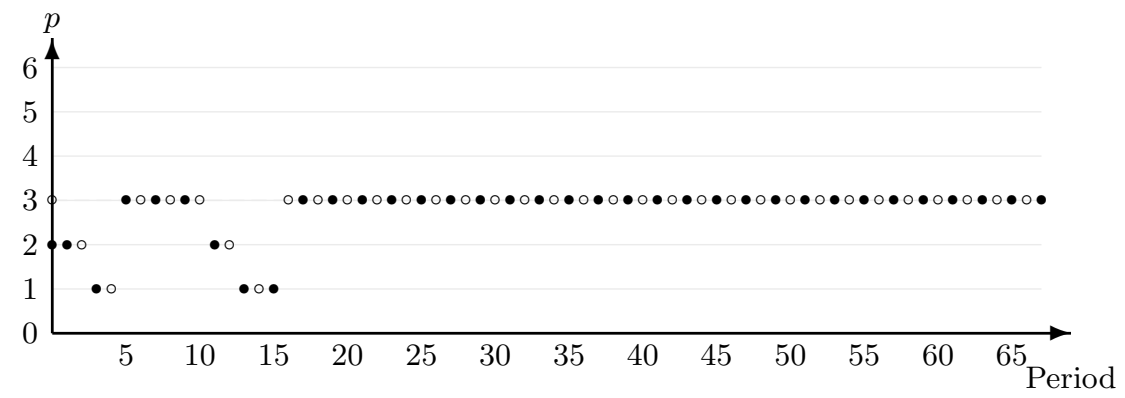

Figure 37: Group AR.4

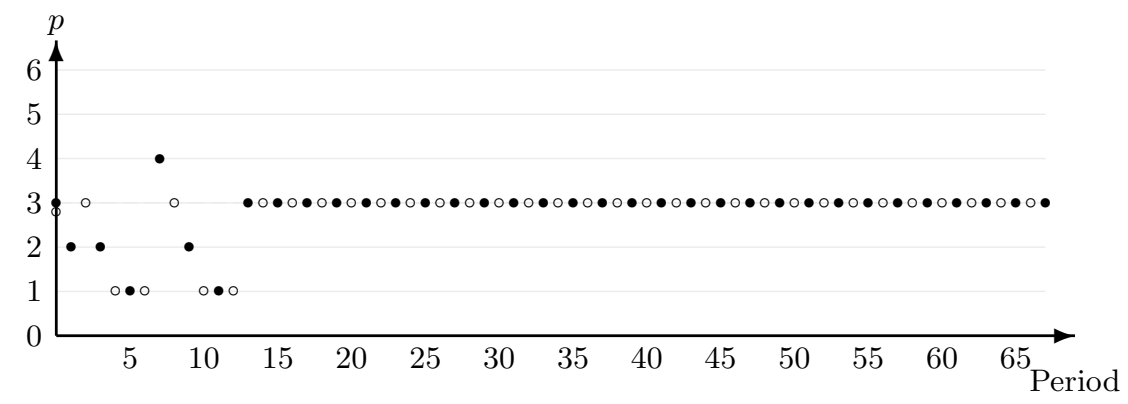

Figure 38: Group AR.5 


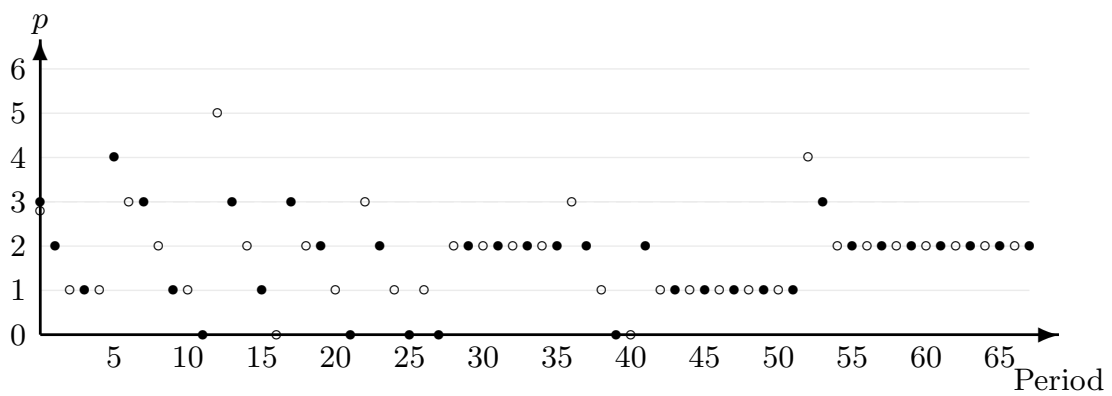

Figure 39: Group AR.6

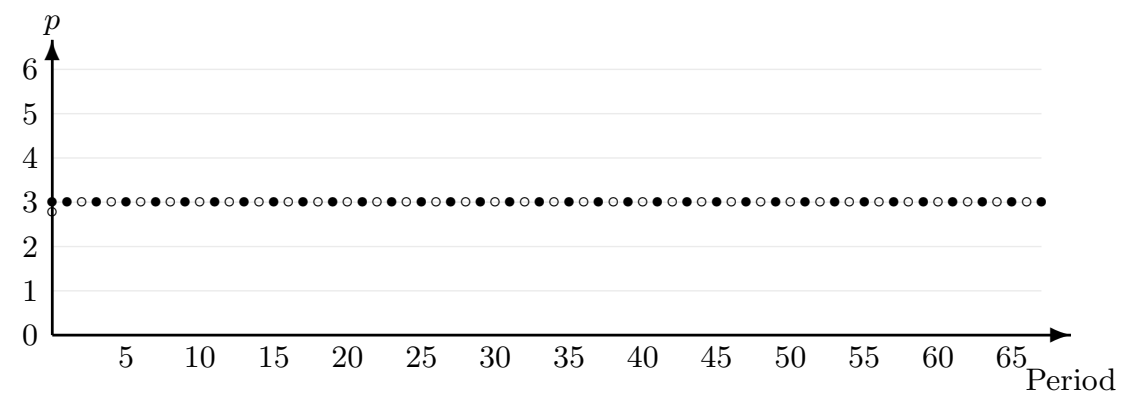

Figure 40: Group AR.7

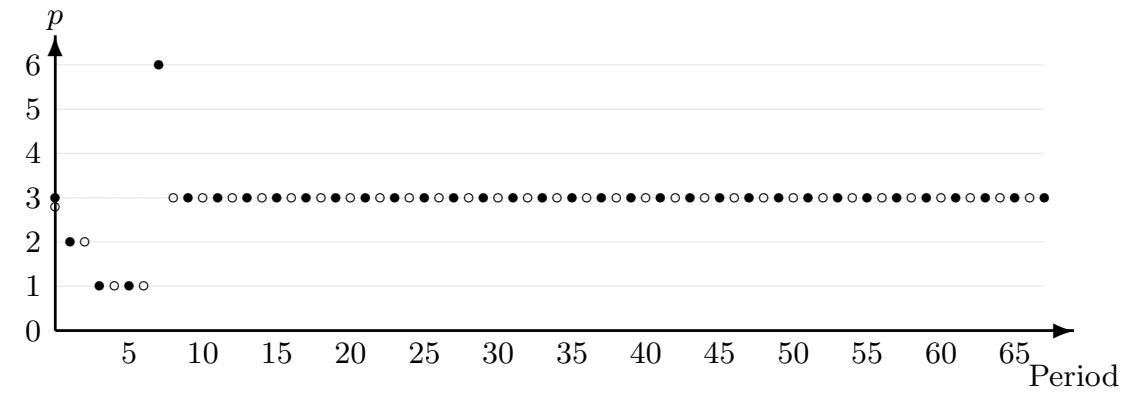

Figure 41: Group AR.8

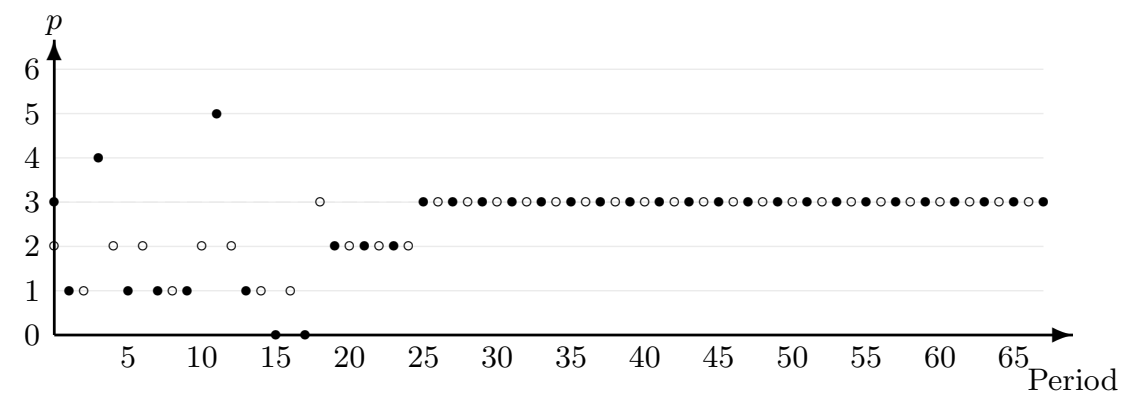

Figure 42: Group AR.9

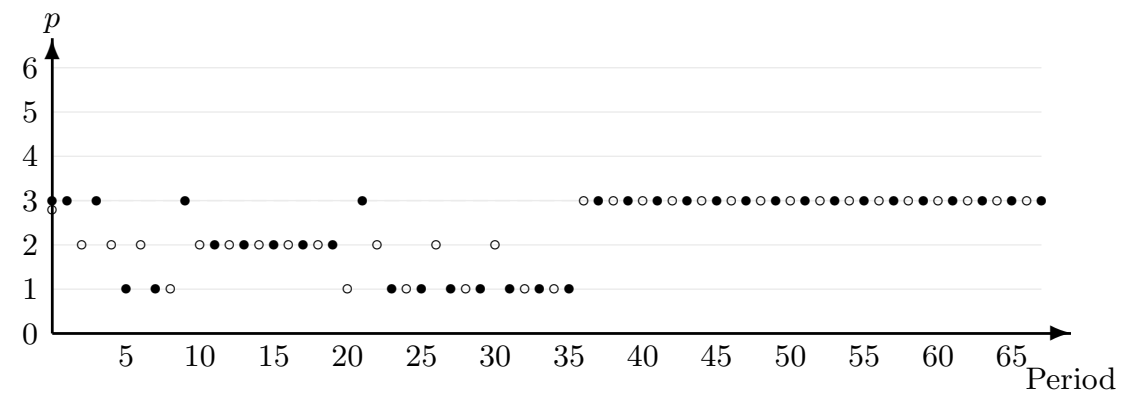

Figure 43: Group AR.10 


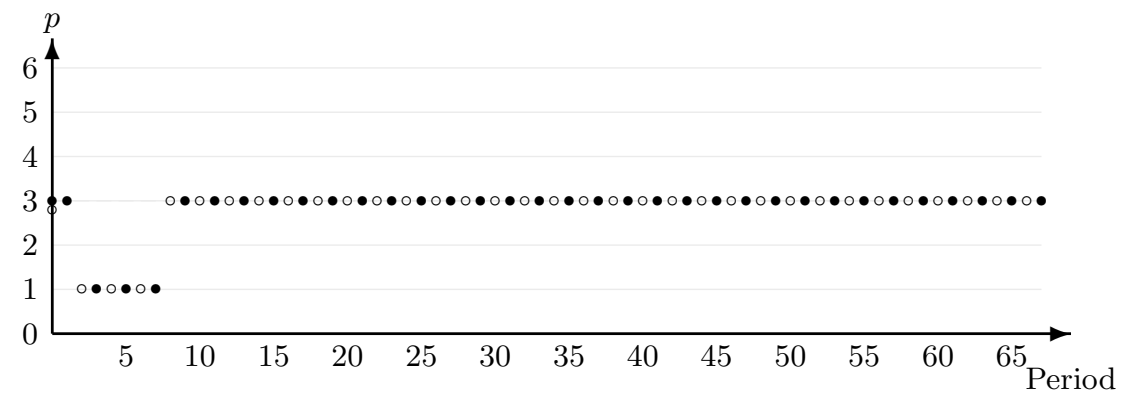

Figure 44: Group AR.11

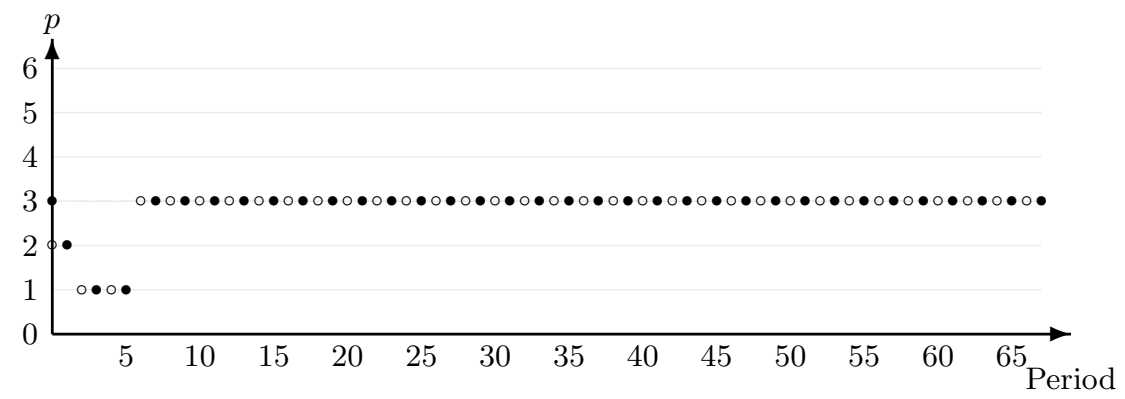

Figure 45: Group AR.12

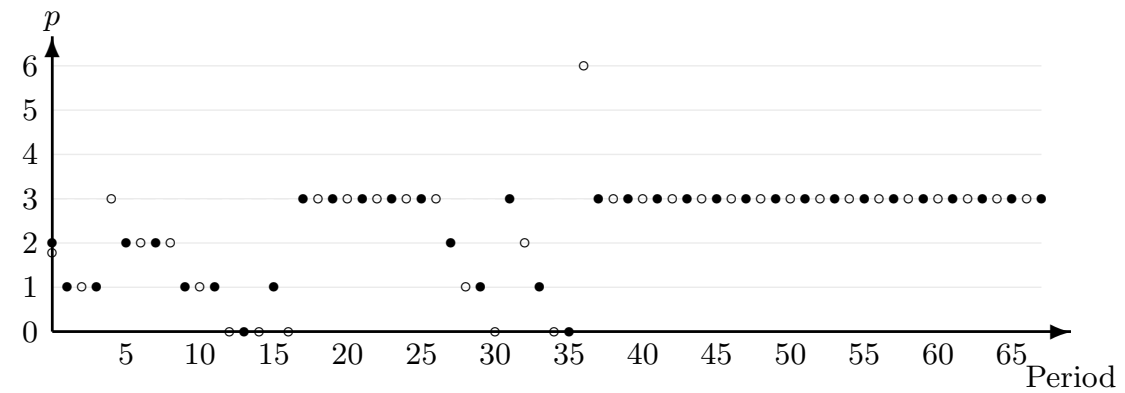

Figure 46: Group AR.13

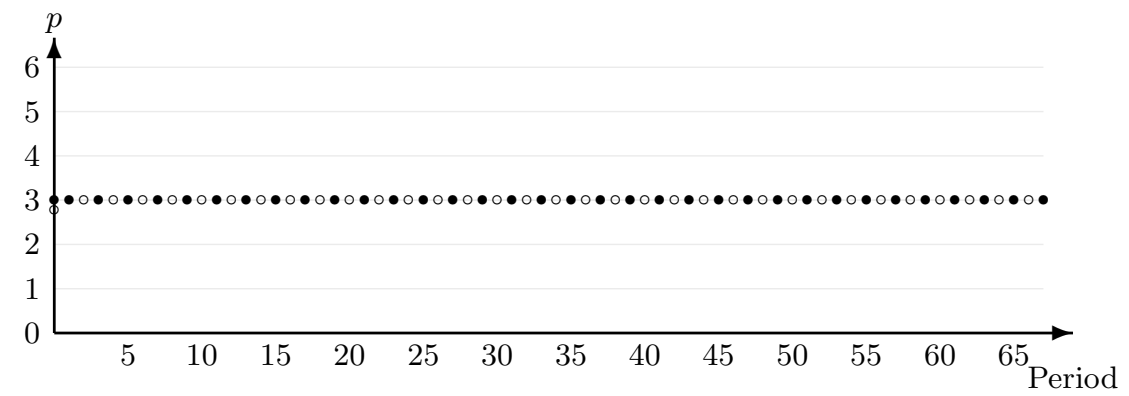

Figure 47: Group AR.14

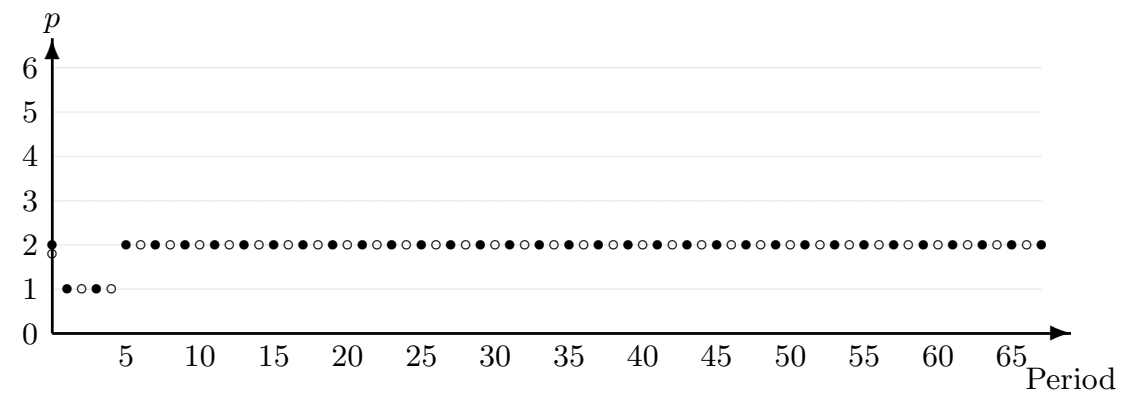

Figure 48: Group AR.15 


\section{A.4 Treatment with alternating moves and fixed ending}

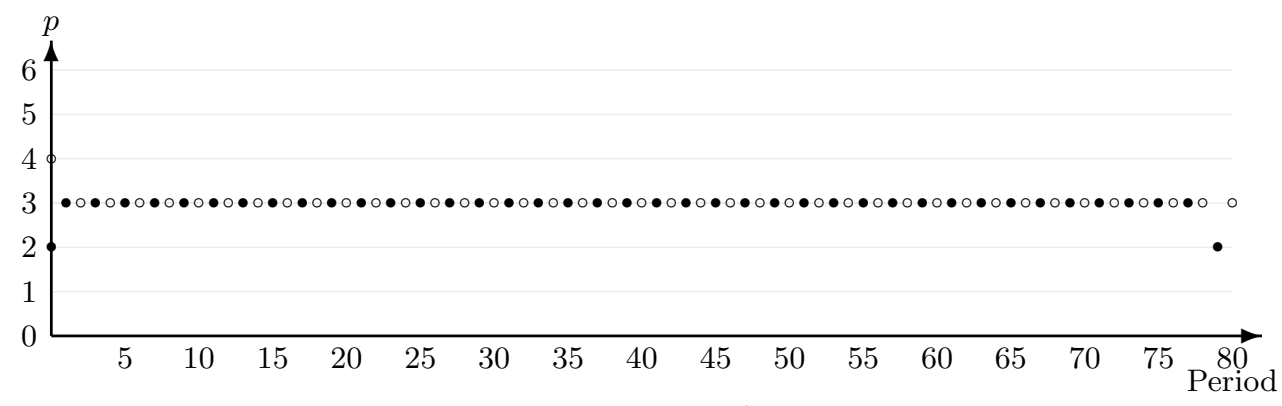

Figure 49: Group AF.1

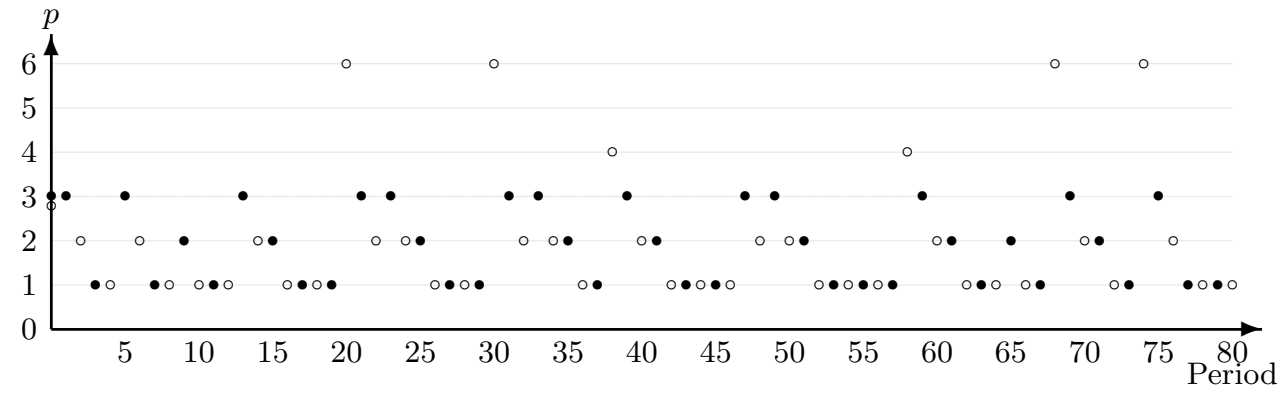

Figure 50: Group AF.2

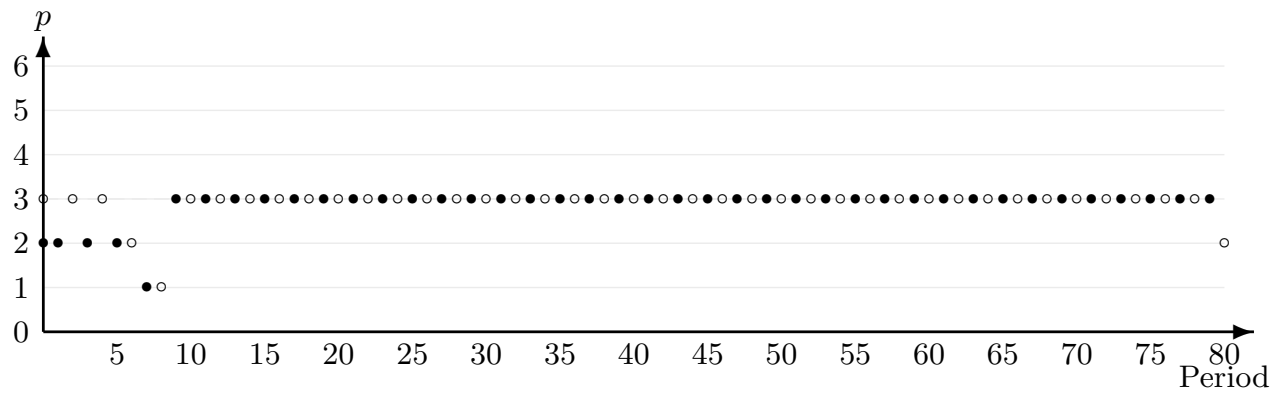

Figure 51: Group AF.3

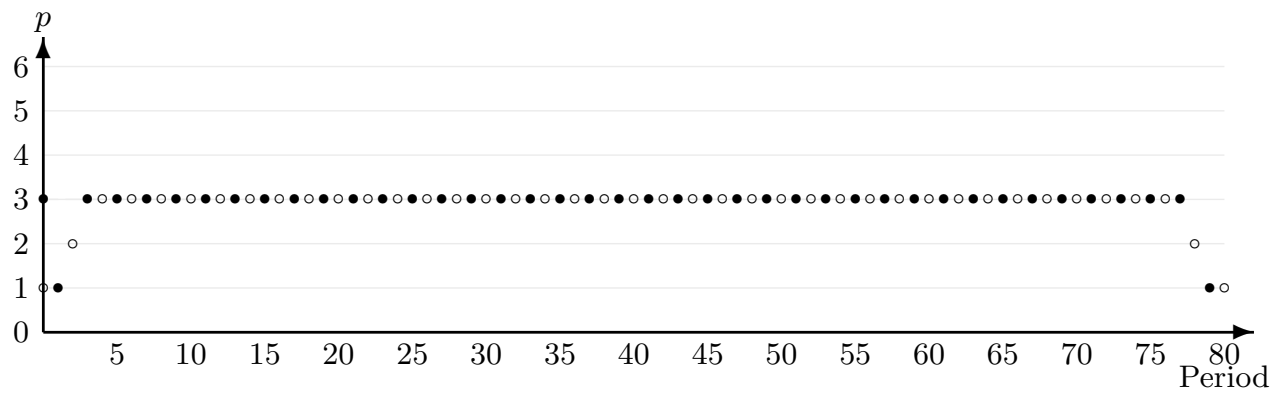

Figure 52: Group AF.4

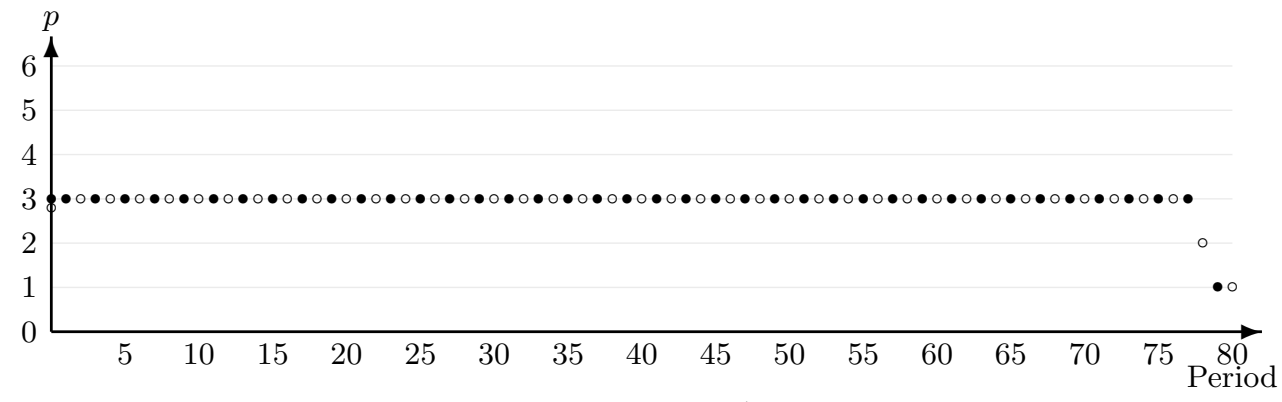

Figure 53: Group AF.5 


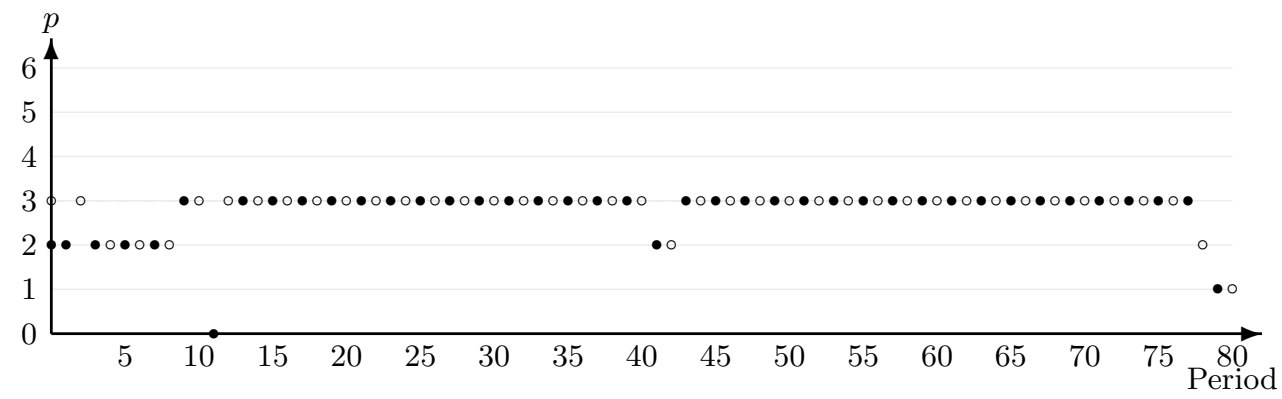

Figure 54: Group AF.6

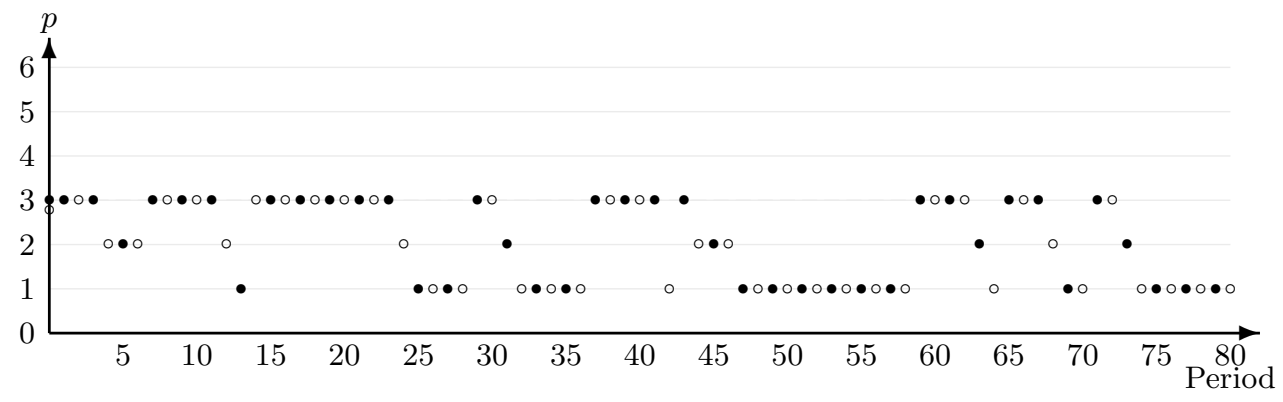

Figure 55: Group AF.7

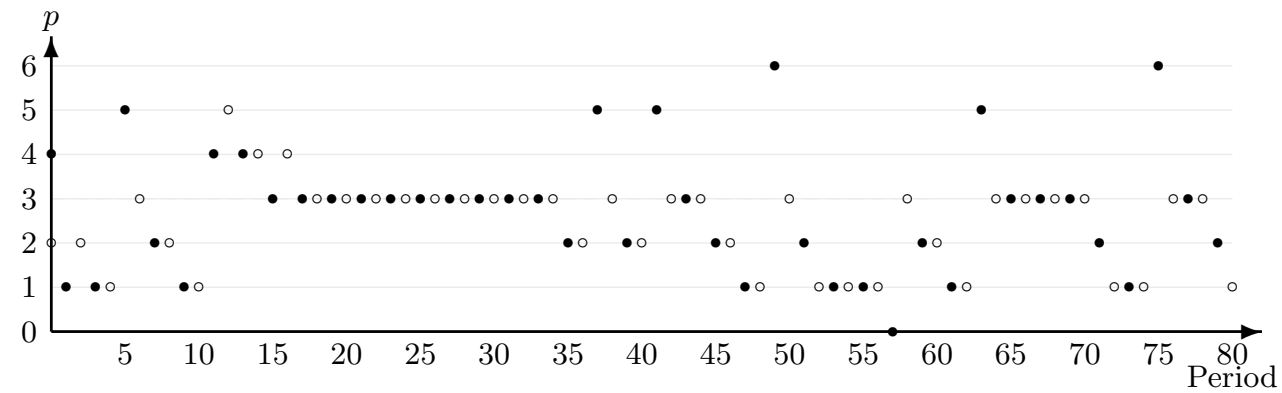

Figure 56: Group AF.8

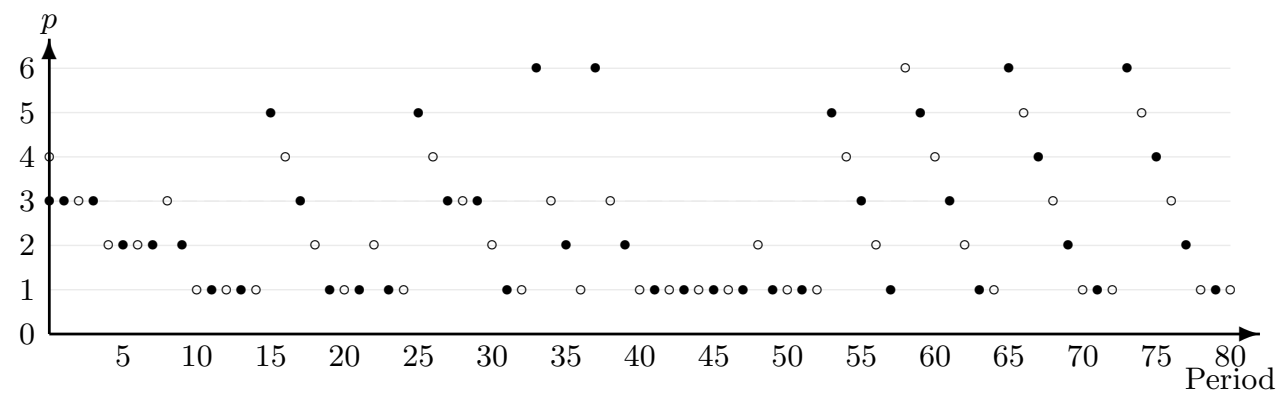

Figure 57: Group AF.9

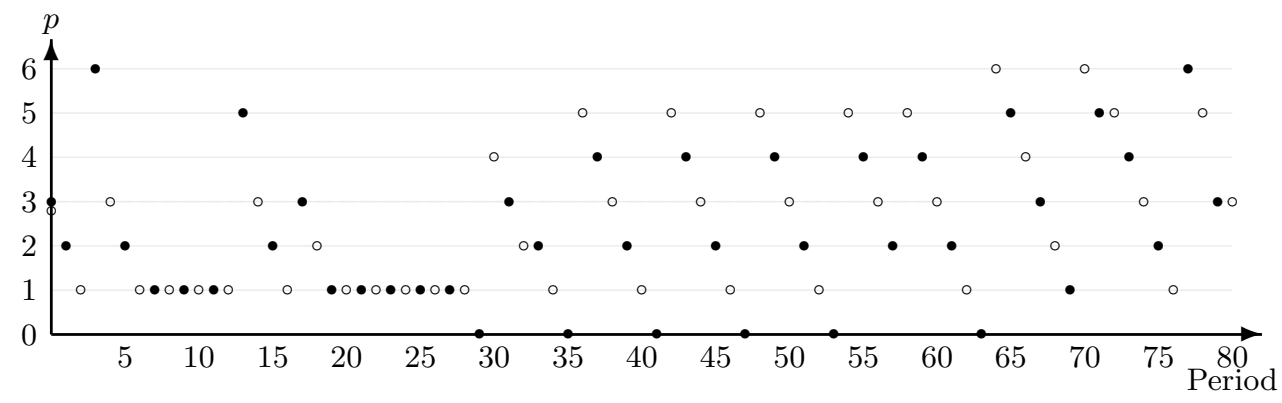

Figure 58: Group AF.10 


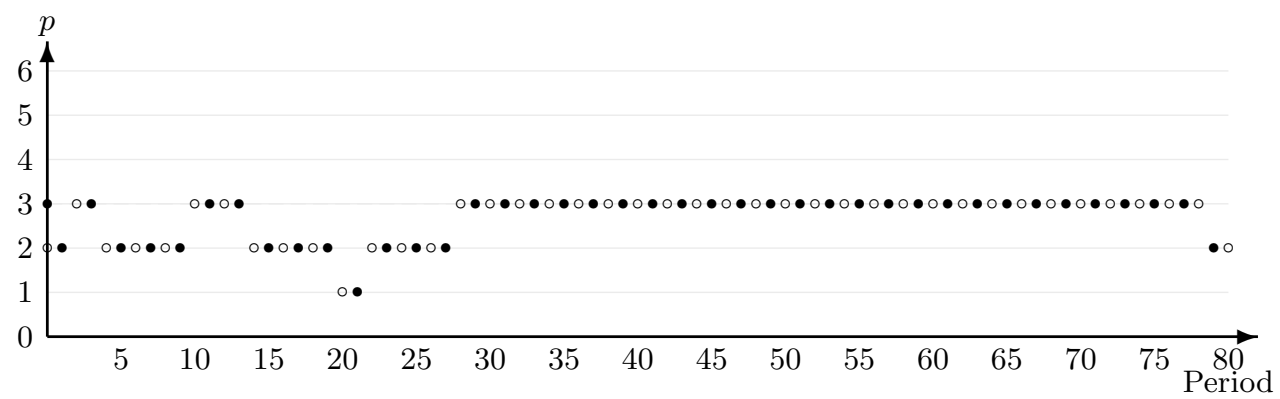

Figure 59: Group AF.11

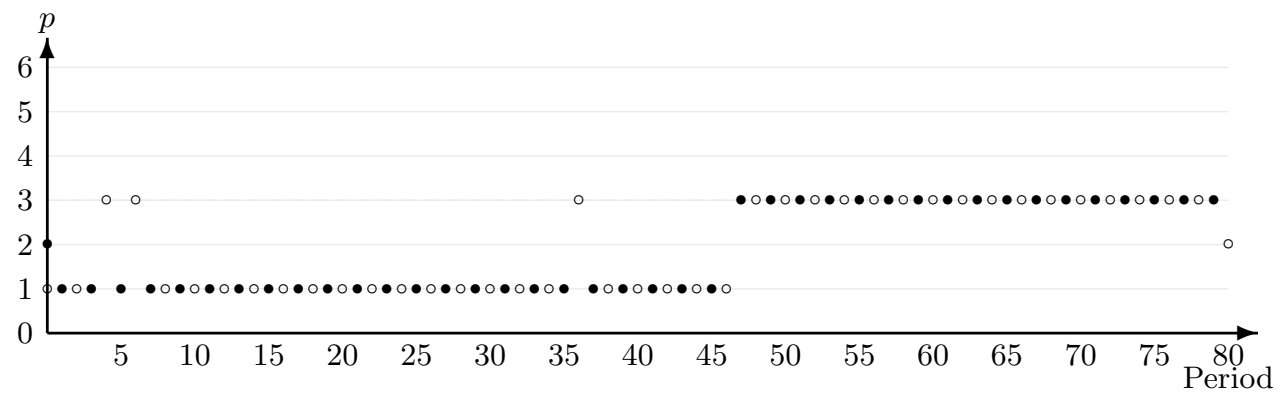

Figure 60: Group AF.12

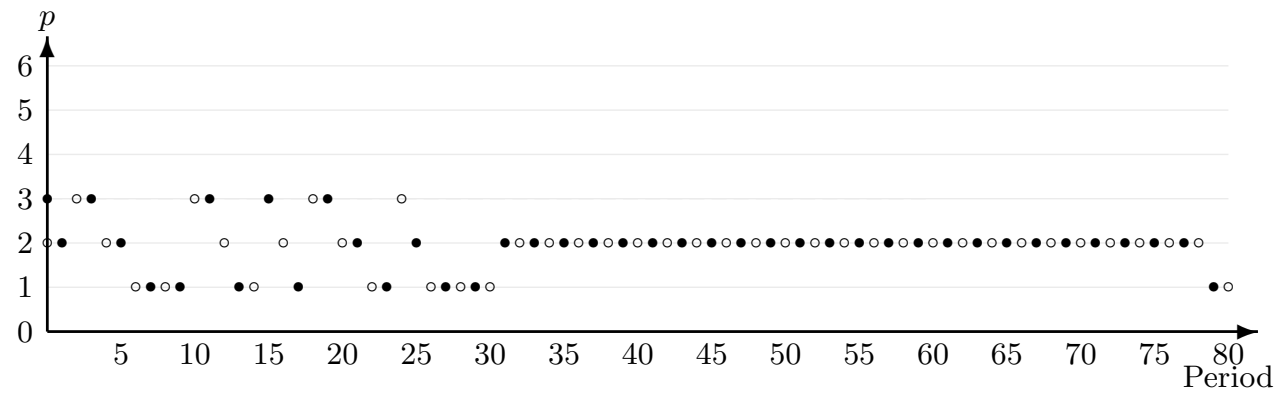

Figure 61: Group AF.13

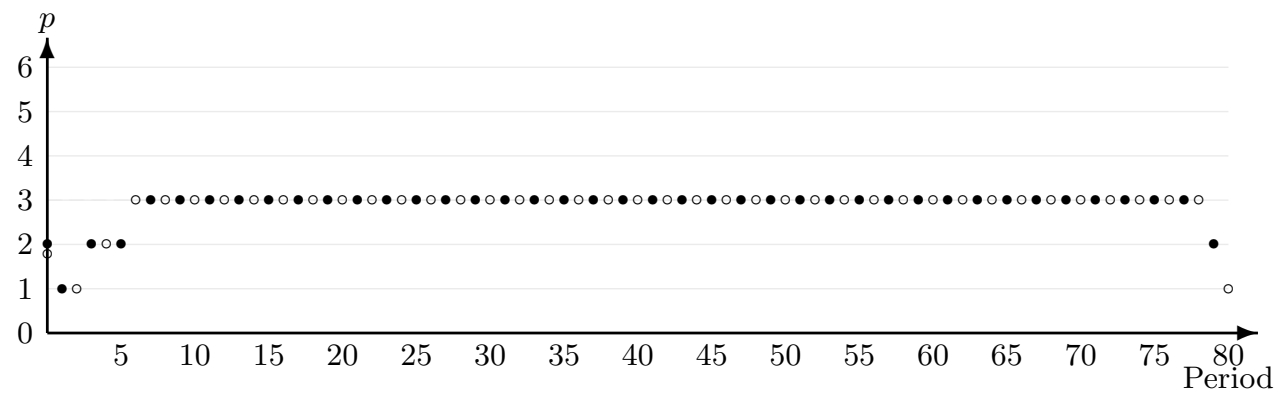

Figure 62: Group AF.14

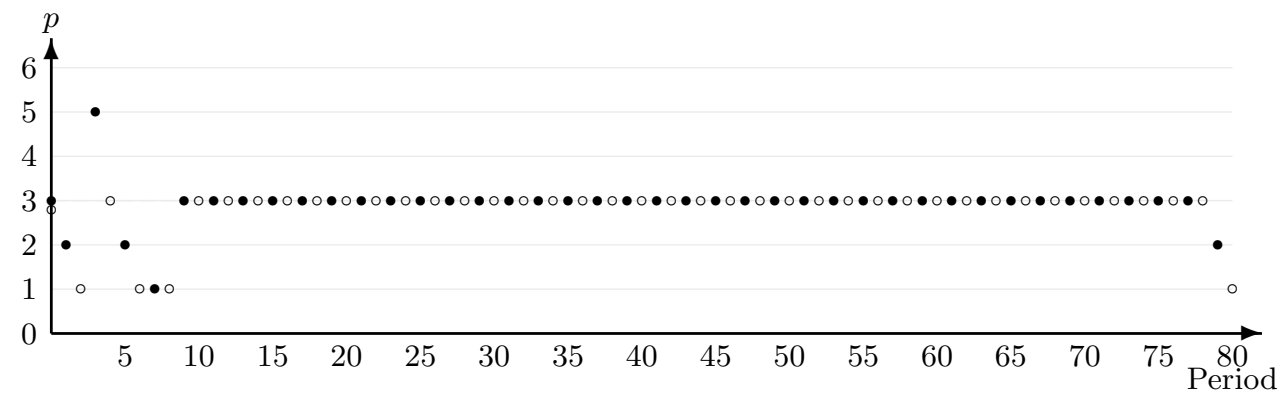

Figure 63: Group AF.15 


\section{B Instructions}

This subsection contains only the instructions for the treatment with alternating moves and random ending. Instructions for the other treatments were in identical phrasings and are available upon request.

Dear participant, welcome to this experiment. You will be compensated according to your performance. In order to ensure that the experiment takes place in an optimal setting, we want to ask you to follow the general rules during the whole experiment:

- Read these instructions carefully! It is important that you understand the rules of this experiment. These instructions are identical for all subjects that participate together with you. If something is not explained well, please raise your hand. Do not ask the question out loud, but wait until one of the experimenters approaches you to answer the question in private.

- Switch off your mobile phone!

- Do not communicate with your fellow students! Even though the experiment may get exiting at times, it is very important that you remain silent through the proceedings.

- Focus on your own computer screen and not on other participants!

- There is paper and a pen on your table which you can use during the experiment.

- After the experiment, please remain seated until you are paid off.

- If you do not obey the rules, the data becomes useless for us. Therefore we will have to exclude you from this experiment and you will not receive any compensation.

Your decisions and earnings in this experiment will remain anonymous.

\section{General set-up}

In this experiment all of you are sellers of a fictitious commodity. You can earn ECU (Experimental Currency Units) which will be exchanged into Euros at the end of the experiment. The exchange rate will be given in the instructions below.

Before the experiment starts, you will be randomly divided into groups of two sellers. You will not know the identity of the seller you are matched with. The groups remain unchanged throughout the whole experiment. 


\section{Procedures}

This experiment consists of multiple periods. In each period, only one of the two sellers can adapt its price. The price of the seller that cannot adapt its price remains equal to its price in the previous period. The seller that can adapt its price switches after each period. Consequently, one seller can adapt its price only in the odd periods, whereas the other seller can adapt its price only in the even periods.

Before setting your price for the current and the subsequent period, you observe the price of the other seller for the current period. Remember that the other seller can adapt its price in the next period, after having observed your price. This procedure of alternating priceadaptation continues until the experiment ends.

Possible prices are the integers between (and including) 0 and 6 . To decide on a price you can select a price on your screen and then click on $O K$ (see the figure below).

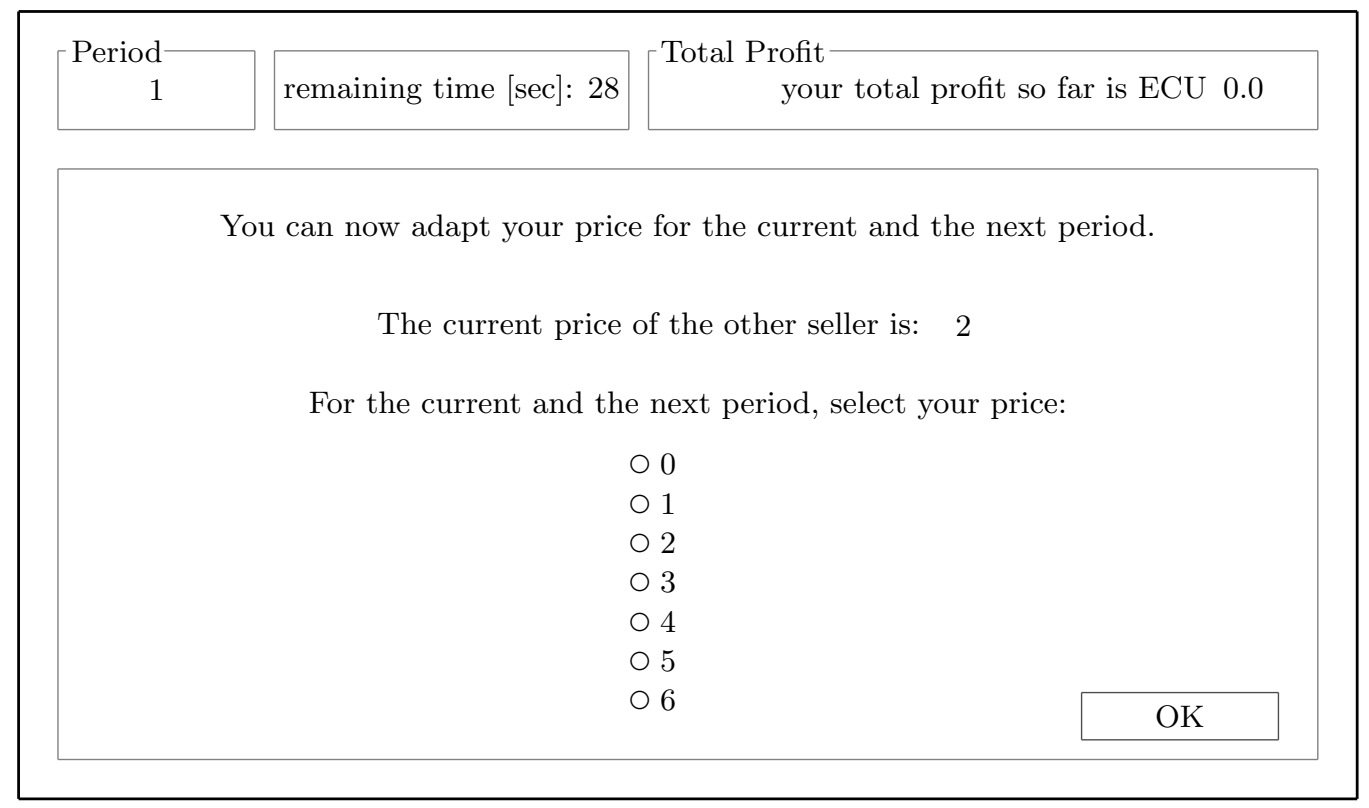

Figure 1: Screenshot of price adaptation screen.

After the seller that could adapt its price has made its decision, the profits for that period are determined. Only the seller that has the lowest price sells output. The amount of output depends on its price. There are no production costs. Hence, the profit for the seller that has the lowest price is equal to the output multiplied by its price. Table 1 shows the output and profit at each possible price for the seller that has the lowest price. The other seller has a profit equal to zero in this period. 


\begin{tabular}{llllllll}
\hline \hline Price & 0 & 1 & 2 & 3 & 4 & 5 & 6 \\
Output & 6 & 5 & 4 & 3 & 2 & 1 & 0 \\
\hline Profit & 0 & 5 & 8 & 9 & 8 & 5 & 0 \\
\hline \hline
\end{tabular}

Table 1: The output and profit for the seller with the lowest price.

In case both sellers have the same price, output is split equally. The profit for each seller is then half of the profit reported in Table 1 at that price.

At the end of each period, both sellers receive an overview of the results of that period. You can observe your price, the price of the other seller, your profit, and your total profit so far. In a period in which you cannot adapt your price, you only observe the result screen of that period.

This procedure continues until the end of the experiment.

\section{Number of periods}

The number of periods in this experiment is unknown until the experiment has ended. After each period, the experiment ends with a probability of 2 percent. This means that with a probability of 98 percent the experiment continues with the next period. The decision to continue or not, is made by a computer. Notice that although you are matched with one other seller, the number of periods played will be the same for all subjects in the current session.

\section{The first period}

Before the procedures above start, it has to be decided who of the sellers is able to adapt its price in the first (and all odd) periods and to which price this seller responds. Therefore, the first period contains an initial period in which both sellers are asked to set an initial price. Next the computer randomly decides which of the two sellers can adapt its price in the odd periods. In the first period this seller will respond to the other's initial price.

\section{Closing}

After the last period of the experiment, we would like you to complete a short questionnaire that will appear on your screen. Payments will be made by the experimenters afterwards.

ECU are transformed into Euros according to the following conversion rate: 20 ECU $=1$ Euro. In addition to your earnings during the course of the experiment, you will also receive a show up fee of 5 Euro.

Before we start with the experiment we want you to answer the questionnaire on the next page. One of the experimenters will go around and check the answers and discuss any problems. 


\section{Control questions}

Please answer the following questions. When you are finished, raise your hand. One of the experimenters will come to you and check whether everything is correct.

1. How many sellers are in your group (including yourself)?

2. Suppose that you can adapt your price in period 4 . What does this imply for your price in period 5 ?

_ My price in period 5 will be equal to my price in period 4 .

_ My price in period 5 can be any integer between (and including) 0 and 6 .

3. Suppose that you can adapt your price in period 4 . What do you know about the price of the other seller in period 5 ?

— The other's price in period 5 will be equal to its price in period 4 .

— The other's price in period 5 can be any integer between (and including) 0 and 6 .

4. Suppose that you can adapt your price in period 4. What does this imply for your price in period $6 ?$

_ My price in period 6 will be equal to my price in period 4 .

_ My price in period 6 will be equal to my price in period 5 .

_ My price in period 6 can be any integer between (and including) 0 and 6 .

5. Suppose you can adapt your price in the current period and the price of the other seller is 5 .

(a) What will be your profit in this period when you set a price of 6 ?

(b) What will be your profit in this period when you set a price of 5 ?

(c) What will be your profit in this period when you set a price of 4 ?

6. Suppose you are currently in period 17 , what is the probability that the experiment continues with period 18 ? 


\section{Mathematica code}

\section{C.1 Input}

(* GLOBAL GAME SETTINGS *)

(* $\mathrm{K}$ : the length of the finite horizon is $2 * \mathrm{~K} *$ )

(* d: the discount factor we set at $1 *$ )

(* Profit: the temporal market profits given the market price *)

$\mathrm{K}=37$;

$\mathrm{d}=1$;

Profit $=\{0,5,8,9,8,5,0\}$;

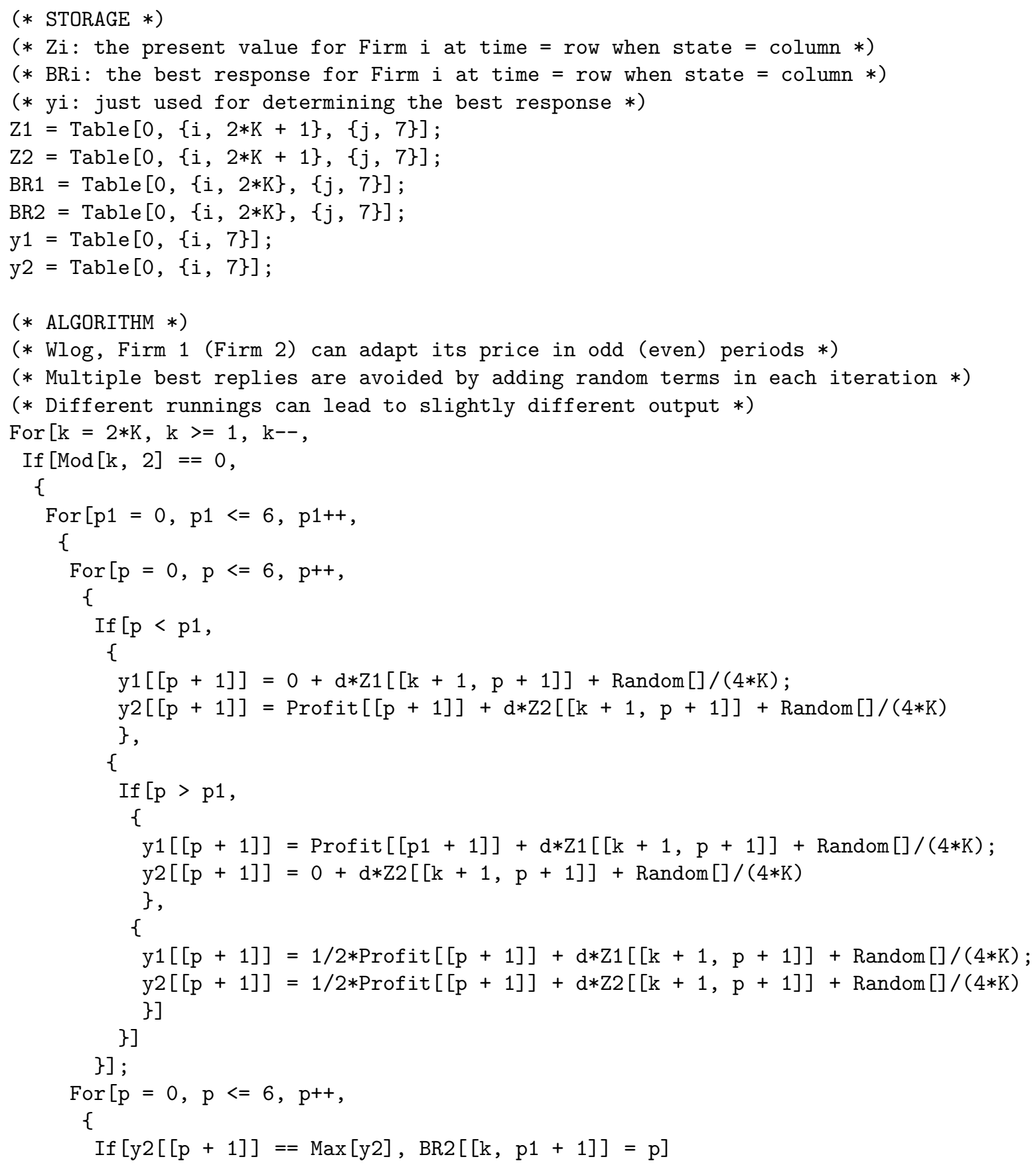




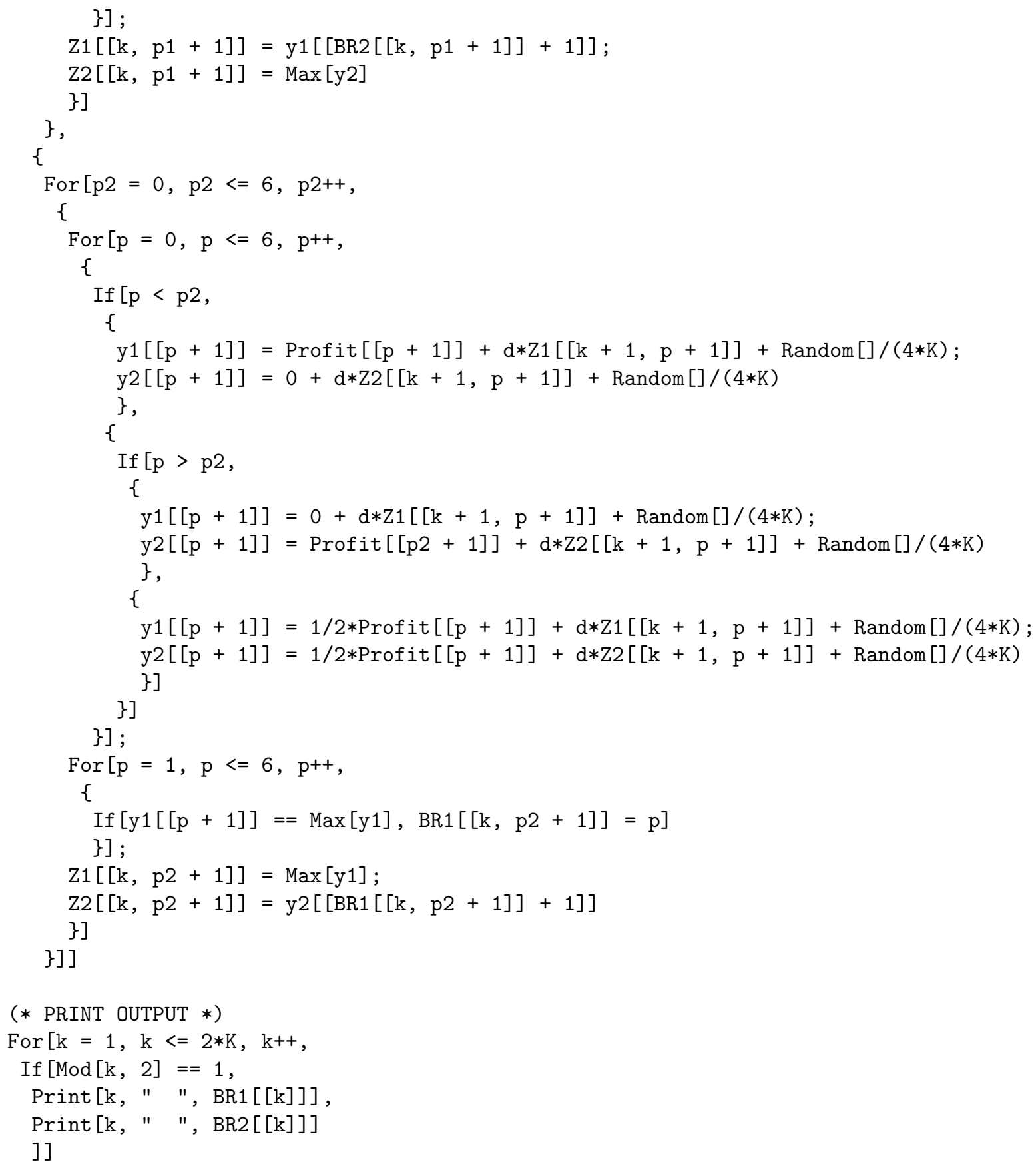

\section{C.2 Output}

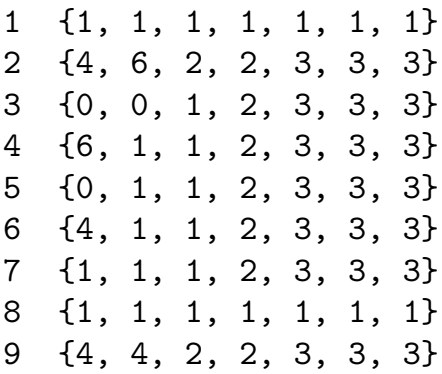

$38\{1,1,1,2,3,3,3\}$

$39\{1,1,1,2,3,3,3\}$

$40\{1,1,1,1,1,1,1\}$

$41\{5,5,2,2,3,3,3\}$

$42\{0,0,1,2,3,3,3\}$

$43\{4,1,1,2,3,3,3\}$

$44\{0,1,1,2,3,3,3\}$

$45\{4,1,1,2,3,3,3\}$

$46\{1,1,1,2,3,3,3\}$ 
